\title{
Savings, asset scarcity, and monetary policy*
}

\author{
Lukas Altermatt ${ }^{\dagger}$
}

April 17, 2019

\begin{abstract}
This paper analyzes optimal monetary policy regarding asset markets in a model where money and savings are essential and asset markets matter. The model is able to explain why different regimes for the correlation of real interest rates and stock price-dividend ratios exist, and offers two explanations why the correlation vanished after 2007: A decrease in inflation or changes in the supply of risky and safe assets. The results on optimal policy show that away from the Friedman rule, fiscal policy can improve welfare by increasing the amount of outstanding government debt. If the fiscal authority is not willing or able to increase debt, the monetary authority can improve welfare of current generations by reacting procyclically to asset return shocks.
\end{abstract}

Keywords: New monetarism, overlapping generations, zero lower bound, optimal stabilization JEL codes: E43, E44, E52, G12, G18

\footnotetext{
*I am grateful to my adviser Aleksander Berentsen for his useful comments, which greatly improved the paper, and to my colleagues Mohammed Ait Lahcen, Florian Madison, and Romina Ruprecht for many insightful discussions. I thank Randall Wright, Cyril Monnet, Tim Kroencke, Gabriele Camera, Sarah Lein, Francesca Carapella, Pedro Gomis-Porqueras, Simon Straumann, and seminar participants at the Summer Workshop in Money, Banking, Payments and Finance 2018 at the Fed St. Louis, the 9th Conference on Growth and Business Cycles in Theory and Practice in Manchester, the 2018 T2M Conference at Université Paris-Dauphine, the 11th RGS Doctoral Conference in Essen, the University of Wisconsin-Madison, the Cadi Ayyad University of Marrakech, the University of Basel, the University of Bern, and the Alumni Conference in Gerzensee for valuable comments and suggestions.

${ }^{\dagger}$ University of Wisconsin-Madison and University of Basel. lu.altermatt@gmail.com
} 


\section{Introduction}

Asset markets are a central part of today's economies, and an important driver for business cycles. Arguably, the last two recessions in the U.S. have been caused by downturns on asset markets. Thus, it is clear that they are also a major factor to consider for monetary policy. However, it remains unclear how exactly monetary policy should take them into account, and how it should react to changes in asset returns. While some economists think that monetary policy should basically ignore asset markets $^{1}$, others like Taylor (2014) claim that the wrong stance of monetary policy regarding asset markets caused the financial crisis of 2007-2009.

One reason why economists disagree on how monetary policy should take asset markets into account is that the (mainstream) literature on monetary policy has mostly ignored financial markets, especially before the financial crisis. In the aftermath of the financial crisis, some parts of the literature started to incorporate financial aspects, but often in an ad-hoc way. The New Monetarist literature following Lagos and Wright (2005) has taken financial assets more seriously and started to integrate them into its models, but focused mostly on their liquidity properties. While liquidity is certainly an important factor to consider, savings properties of financial assets, and life-cycle considerations in general, also appear to be central to their pricing. So to properly study the effects of monetary policy on financial markets, I think one needs a model where both liquidity and life-cycle considerations are essential.

This paper aims to better integrate the role financial markets play for savings into the New Monetarist literature. More precisely, this paper has three goals: (1) I want to build a tractable model that takes both liquidity and life-cycle considerations seriously; (2) I want to use this model to explain some stylized facts about the correlation of bond and equity returns, in order to ensure that the model is able to capture the relevant mechanisms regarding the substitutability of different assets; and (3) I want to study optimal monetary and fiscal policy within this model, in order to determine whether, and under which circumstances, monetary policy should react to asset return shocks.

To reach the first goal, I combine two standard frameworks. To study the role of savings and make life-cycle considerations essential, I use the overlapping-generations (OLG) model based on Wallace (1980), as it is the most natural framework. While there are many OLG papers in which money plays a role, money is used only as a savings instrument in most, if not all, of them. Since

\footnotetext{
${ }^{1}$ see e.g. Bernanke and Gertler (2001).
} 
I want to build a model where money can be used not only as a savings instrument, but also as a medium of exchange instrument for transactions, I combine the OLG structure with the Lagos and Wright (2005) (LW) framework, as money is essential for transactions in this class of models ${ }^{2}$.

Regarding the second goal, I analyze U.S. data on bond and equity returns. The data shows that since at least 1982, the dividend-price ratios of equity and real interest rates were negatively correlated in the United States. Around the beginning of the financial crisis however, this correlation ceased to exist. The regime change occurred more or less at the same time as the zero lower bound was hit. With the help of the model, I want to understand why different regimes regarding the correlations exist, and how an economy can move from one regime to the other. Being able to explain these stylized facts is important for two reasons: First, the question itself is relevant, as understanding why such regime changes occur can help policymakers and investors to make decisions. Second, ensuring that the model matches these stylized facts increases the credibility of the model, and makes the policy analysis, and thus the third goal of the paper, more relevant.

Combining the OLG and LW frameworks allows me to create a model in which prices for government bonds and risky assets are determined endogenously. In the model, agents can use government bonds (nominal, safe assets), equity (real, risky assets), or fiat money to save. Fiat money is essential for intra-period trade, but it is typically dominated in terms of the rate of return by the other assets, so it is not used for savings in equilibrium, except at the zero lower bound (ZLB). For simplicity, I assume that bonds and equity cannot be used for intra-period trade (I relax

\footnotetext{
${ }^{2}$ There have been a few other papers that combined the OLG structure with the money search environment of LW, such as Zhu (2008), Jacquet and Tan (2011), Waller (2009), or Hiraguchi (2017). As far as I am aware, I am the first one to combine LW and OLG in order to study the effect of monetary policy on asset prices and financial markets. In the papers mentioned, fiat money is the only asset except for Hiraguchi (2017), which has fiat money and capital. My model also differs from these cited here because I assume that only buyers have a finite life-cycle, while sellers have an infinite lifespan. Apart from Jacquet and Tan (2011), my model is also the only one that assumes fixed types, which means that I abstract from preference shocks, which play a somewhat important role in the other papers. Zhu (2008) shows that under some parameters, a positive inflation rate can be welfare increasing, because lower savings (due to inflation) make sellers produce more for the same price, thus creating a positive externality for buyers. Hiraguchi (2017) extends the model of Zhu (2008) by adding capital and shows that a deviation from the Friedman rule is optimal even if the government has access to age-specific lump-sum taxes. Waller (2009) studies optimal taxation in a model that builds on Zhu (2008), but includes private information about preferences. He shows that the constrained optimum can be replicated with a nonlinear consumption tax and zero lump-sum taxes. If nonlinear taxes are not available, it is optimal for the government to implement a positive inflation rate as part of the optimal taxation scheme under some parameters. Jacquet and Tan (2011) introduce productivity shocks in the CM that affect buyers and sellers differently, and show that under these circumstances, monetary policy can overcome bargaining frictions in the DM.
} 
this assumption in Appendix A). There are two types of agents in the model, called buyers and sellers. Buyers have a finite life-cycle and cannot work in the last period of their life. This makes savings essential for them, because it is the only way to acquire consumption in the last period. Sellers on the other hand have an infinite lifespan, which means that their investment decisions are solely driven by arbitrage considerations. Although bonds have no liquidity properties, a ZLB (i.e., a situation where the interest rate on bonds is equal to zero) can occur. This is because buyers demand a positive amount of bonds for any nonnegative interest rate. If their demand is higher than the supply of bonds at positive interest rates, the market can only clear at the ZLB, and buyers use both bonds and money to save. In other words, the ZLB is hit due to a scarcity of savings instruments that leads to an increase in the stochastic discount factor (SDF).

If the supply of bonds is plentiful in this economy, the risk-averse buyers don't want to hold risky assets. In this case, the price of risky assets has to equal their discounted expected payoff, because sellers are indifferent about holding them at this price. If the bond supply is scarce, interest rates are low, and buyers are willing to hold some amount of risky assets in order to increase the expected return of their savings portfolio. The lower the bond interest rate, the more risky assets buyers are willing to hold - this is a portfolio balance effect. As long as the marginal investor in risky assets is a seller, this portfolio balance effect does not affect the price of risky assets. In this regime, there is no correlation between bond and equity returns, because a decrease in bond interest rates leads to an increase in demand for risky assets, but no changes in their price. However, once the demand for risky assets by buyers becomes sufficiently high, the price of risky assets has to increase to clear the market. In this regime, there is a positive correlation between the return on bonds and equity. In general, one can say that the returns are positively correlated if all assets are scarce, while there is no correlation if only bonds (or safe assets in general) are scarce, and the supply of risky assets is plentiful.

In the data, one can observe that the U.S. moved from a regime with positive correlation away from the zero lower bound to a regime at the zero lower bound with no correlation. There are two reasons in the model why an economy can move from a regime with negative correlation away from the zero lower bound to a regime without correlation at the zero lower bound: (1) a decrease in inflation, or (2) a simultaneous decrease in the supply of safe assets accompanied by an increase in the supply of risky assets. I argue that both of these situations occurred during and after the financial crisis. Inflation decreased in the United States as well as in most other developed economies, and many assets that were considered safe before the financial crisis, such as mortgage-backed securities or sovereign bonds from southern European countries, turned out to be risky at that 
time. Thus, the model is able to suggest plausible explanations for the transition from a world where dividend-price ratios and real interest rates were strongly correlated to one where they are uncorrelated.

The results I find for optimal monetary and fiscal policy are novel and interesting: As it is standard in this type of models, the Friedman rule (i.e., setting the opportunity cost of holding money to zero) allows the first-best to be achieved. Away from the Friedman rule, the fiscal authority can increase welfare by issuing a sufficient number of government bonds. However, in reality it may not be feasible politically to run the Friedman rule or to issue a large amount of public debt. If that is the case, then the monetary authority can use an optimal stabilization policy which applies different inflation rates after equity market shocks in order to increase welfare. The optimal policy is procyclical, i.e., inflation should be set higher when stock market returns are high and lower when stock market returns are low. Such a policy is able to minimize or even completely eliminate the risk that savers face by creating a negative correlation between the returns of nominal government bonds and real assets.

Besides this main result, there are two other interesting findings regarding monetary policy: The model shows that (1), quantitative easing reduces the welfare of future generations, because it reduces the returns on all savings instruments; and (2), increasing the inflation target reduces the risk of hitting the zero lower bound, but still decreases welfare overall.

\subsection{Related Literature}

This paper is mainly related to the literature on monetary policy and asset prices. As already mentioned above, some economists think that monetary policy should not directly react to asset markets. After the crisis, this view was challenged by several authors. In an empirical analysis, Schularick and Taylor (2012) show that periods of financial instability are often caused by credit booms that have gone wrong, and they advocate that monetary policy be employed to control such booms. However, Ajello et al. (2016) conclude in a recent empirical analysis that the optimal monetary policy response to credit conditions is only marginally different from a response that exclusively takes price level stability and output into account. Stein (2012) creates a model in which private money creation by banks leads to an externality that can be countered by regulation. Nistico (2012) found that an interest-rate rule which responds to deviations in stock prices could lead to additional instability. Gali $(2014,2017)$ uses an OLG framework to study the link between monetary policy and rational asset price bubbles. He finds that a stronger interest rate response to bubble fluctuations can increase the volatility of the bubble component, and that stabilization of 
the bubble itself calls for a negative interest rate response. In the more recent paper, he finds that an interest rate rule which responds directly to the bubble can succeed in fine-tuning the economy under some circumstances. In contrast, a policy that directly targets inflation attains the same stabilization effects without some of the destabilizing risks of the interest rate rule.

Within the New Monetarist literature, one of the first papers to study the effect of monetary policy on asset prices was Geromichalos et al. (2007). They show that asset prices increase with inflation due to no arbitrage considerations. In their model, assets are primarily valued for their liquidity properties. Lagos (2010) builds a model with both safe and risky assets, and uses it to study the equity-premium puzzle and the risk-free rate puzzle. In Lagos (2010), assets pricing is also driven by liquidity considerations. In Lester et al. (2012), the authors build a model where liquidity and recognizability of assets are endogenous, and analyze the effects of monetary policy within this framework. In a more recent paper, Geromichalos et al. (2018) distinguish between safety and liquidity and analyze whether the common assumption that safe assets are also more liquid is justified.

The New Monetarist literature also made important contributions to more general aspects of optimal policy. Aruoba and Chugh (2010) show that in a model where fiat money is essential and capital is an input of the production function, the Friedman rule is typically not optimal, and the optimal capital income tax is not zero. Gomis-Porqueras and Peralta-Alva (2010) show that production subsidies can restore the efficiency of monetary equilibria if bargaining frictions exist. When lump-sum money transfers are not available, a sales tax can be used to increase welfare, and the Friedman rule is only optimal if the buyer has low bargaining power.

The optimal stabilization policy I describe in this paper shares some similarities with those in Berentsen and Waller $(2011,2015)$, but the mechanisms behind the policy are different. I explain these differences in Section 5, after deriving the optimal stabilization policy.

My paper is also similar in some ways to the work of Caballero et al. (2017) and especially Caballero and Farhi (2018). In their paper, Caballero and Farhi show that a shortage of safe assets can lead to a situation that they label the safety trap, which is similar to a liquidity trap but has even more severe effects. Such a safety trap is deflationary and leads to sharp decreases in output in their model. To obtain these results, Caballero and Farhi add nominal rigidities, two types of agents and financial frictions to a perpetual youth OLG model. Although the model I present here shares similarities with Caballero and Farhi (2018), the focus is different, as I am more interested in the behavior of asset prices and what consequences these have for agents, and subsequently how 
monetary policy can improve the outcome.

Other papers studying the effects of shortages of safe assets are Caballero et al. (2008), Caballero and Krishnamurthy (2009), Bernanke et al. (2011), Barro et al. (2017), and He et al. (2015). The macroeconomic effects caused by a shortage of safe assets found in these studies mostly correspond to the results from Caballero and Farhi (2018).

My paper is also related to the literature on liquidity traps, e.g., Krugman et al. (1998), Eggertsson and Woodford (2003, 2004), Eggertsson and Krugman (2012), Williamson (2012, 2016), Rocheteau et al. (2017), Guerrieri and Lorenzoni (2017), Cochrane (2017), Geromichalos and Herrenbrueck (2017), or Altermatt (2017). While some of these papers (e.g., Williamson $(2012,2016))$ focus on the liquidity services provided by bonds, others such as Eggertsson and Krugman (2012) explain the liquidity trap by financial frictions such as tightened borrowing constraints. In the model presented here, economies do not become stuck at the zero lower bound for these reasons, but simply because certain assets are essential for savings and thus agents are willing to pay a premium for them.

\section{$1.2 \quad$ Data}

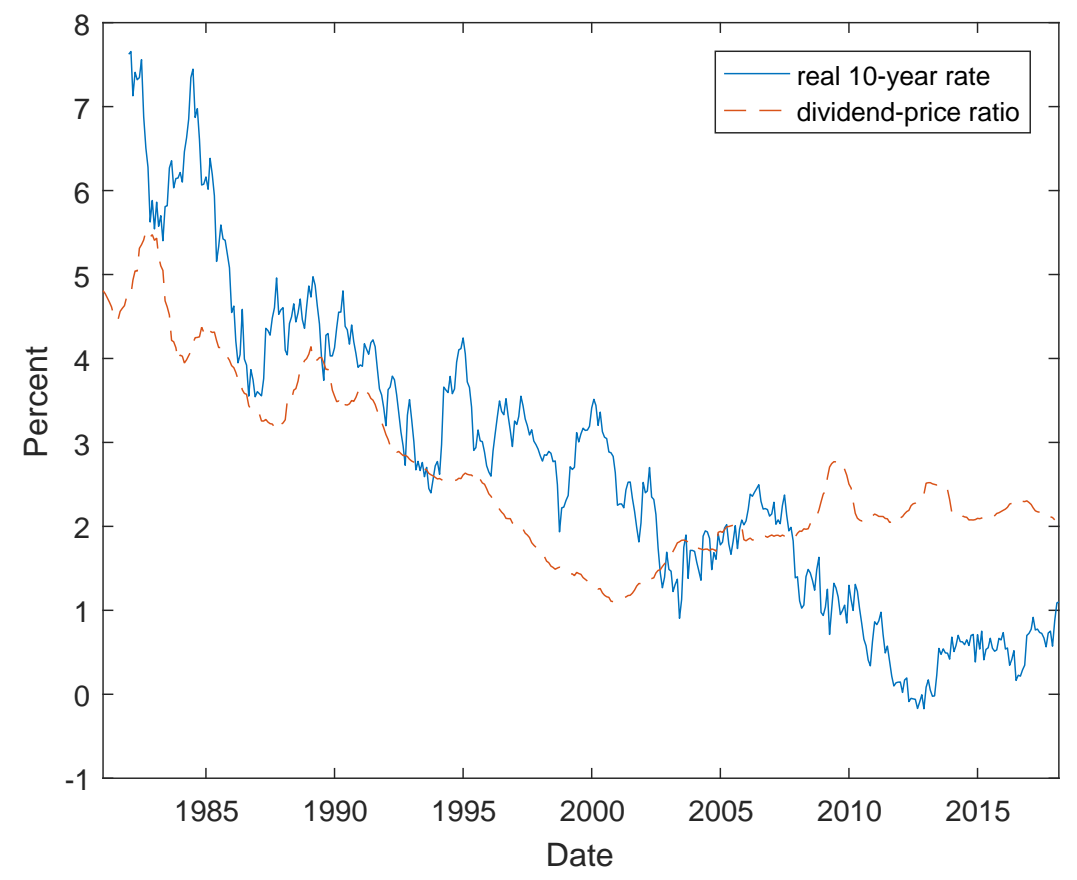

Figure 1: Real ten-year interest rates and the dividend-price ratio for US equity.

As mentioned above, the model is able to match stylized facts about the correlation between 
the dividend-price ratio ${ }^{3}$ of stocks and the real interest rate. Figure 1 shows the real ten-year interest rate for the United States and the dividend-price ratio for US-traded equity from 1982 until $2017^{4}$. It is clearly visible from the graph that there is a strong correlation between these two time series. The correlations for the whole sample as well as for two subsamples are listed in table 1.

\begin{tabular}{lc}
\hline Time period & correlation \\
\hline \hline $1982-2017$ & 0.738 \\
\hline $1982-2007$ & 0.870 \\
\hline $2008-2017$ & -0.029 \\
\hline
\end{tabular}

Table 1: Correlations between real interest rates and dividend-price ratios.

Table 1 shows that there is a strong positive correlation for the whole sample. However, a closer inspection shows that the correlation was even stronger from 1982 until 2007, but that it vanished afterwards, approximately at the time the financial crisis occurred. Since then, the dividend-price ratio has been quite stable, while the real interest rate decreased further until approximately 2013, and has subsequently recovered. This suggests that there was a structural break in the relationship between (expected) inflation, bond prices, and asset prices during or after the financial crisis. As already explained above, my model is well suited to explain such structural breaks, as it exhibits several different equilibrium regimes.

The rest of the paper is organized as follows. In Section 2, the environment is explained. Section 3 lays out the equilibrium in the economy, and Section 4 explains how to interpret the model empirically. In Section 5, I analyze the optimal monetary and fiscal policy. Finally, Section 6 concludes.

\footnotetext{
${ }^{3}$ While the price-dividend ratio is the more common measure, I use the dividend-price ratio here, because the correlation is more clearly evident in this case. Given that both the real interest rates and the price-dividend ratio depend negatively on the respective asset prices, a positive correlation between these variables therefore also indicates a positive correlation between bond and asset prices, other things equal.

${ }^{4}$ Data on real interest rates is taken from the Federal Reserve Bank of Cleveland. The data on the dividend-price ratio is based on the Center for Research in Security Prices' (CRSP) measures of value-weighted return including and excluding dividends for all equities traded in the U.S. The calculation of the dividend-price ratio follows John Cochrane: https://johnhcochrane.blogspot.ch/2018/02/stock-gyrations.html. His blog post also contains the graph presented here.
} 


\section{The environment}

Time is discrete and continues forever. Each period is divided into two subperiods, called centralized market $(\mathrm{CM})$ and decentralized market $(\mathrm{DM})$. At the beginning of a period, the $\mathrm{CM}$ takes place, and after the CM closes, the DM opens and remains open until the period ends. In any period $t$, there is a measure $N_{t}$ of buyers born. Buyers live for three subperiods, i.e., generation $t$ buyers are born at the beginning of the $\mathrm{CM}$ of period $t$, continue to the $\mathrm{DM}$ of period $t$, and then to the CM of period $t+1$, at the end of which they die. There is also a measure $N_{t}$ of infinitely lived sellers alive in period $t^{5}$. The population growth rate is assumed to be constant over time and is defined as $\frac{N_{t}}{N_{t-1}}=n$. Young buyers and all sellers are able to produce a general good $x$ in the CM. Sellers can produce a special good $q$ in the DM that gives utility to buyers. In the DM, young buyers and sellers are matched bilaterally, and buyers can make take-it-or-leave-it offers. In the $\mathrm{CM}$, a centralized market exists for the general goods produced by young buyers and sellers, and sellers as well as old buyers gain utility from consuming them. Neither general goods nor special goods can be stored by agents. The preferences of buyers are given by

$$
\mathbb{E}_{t}\left\{-h_{t}^{y}+u\left(q_{t}^{y}\right)+\beta U\left(x_{t+1}^{o}\right)\right\}
$$

Equation (1) states that buyers obtain disutility $h$ from producing in the CM, obtain utility $u(q)$ from consuming in the $\mathrm{DM}$ and $U(x)$ from consuming in the $\mathrm{CM}$ when they are old ${ }^{6}$, and that they discount the second period of their life by a factor $\beta \in(0,1)$. Actions occurring in the first period of a buyer's life (when young) are indicated by a superscript $y$, while actions occurring in the second period of a buyer's life (when old) are indicated by a superscript $o$. Assumptions on the utility functions are that $U(0)=u(0)=0, U^{\prime}(0)=u^{\prime}(0)=\infty, u^{\prime}(q)>0, u^{\prime \prime}(q)<0, U^{\prime}(x)>0$, and $U^{\prime \prime}(x)<0$.

The preferences of the sellers are given by

$$
\mathbb{E}_{0} \sum_{t=0}^{\infty} \beta^{t}\left(x_{t}^{s}-h_{t}^{s}-q_{t}^{s}\right) .
$$

Equation (2) states that sellers discount future periods by a factor $\beta \in(0,1)$, obtain linear utility from consuming $x$ in the $\mathrm{CM}$, a linear disutility $h$ from producing in the $\mathrm{CM}$, and linear

\footnotetext{
${ }^{5}$ Possible interpretations of the two types of agents are explained in section 4.2.

${ }^{6}$ The OLG structure allows to incorporate nonlinear preferences in the CM without losing the tractability of the Lagos and Wright (2005) model. Lagos (2010) achieved something similar by adding another good, called apples, to the CM utility function in order to include risk-aversion. However, agents in his model still have the ability to produce general goods at linear disutility during the CM, so instead of saving, they could work later in order to obtain consumption. The crucial change in my model is thus not the concavity of $U(x)$, but the absence of the ability to work for old buyers.
} 
disutility $q$ from producing in the DM. Furthermore, I define $q^{*}$ as $u^{\prime}\left(q^{*}\right)=1$ and $x^{*}$ as $U^{\prime}\left(x^{*}\right)=1$, i.e., as the socially efficient quantities. The variables relating to the sellers are indicated by a superscript $s$. I assume that agents cannot commit to any future payments.

There is also a monetary and a fiscal authority. The monetary authority issues fiat money $M_{t}$, which it can costlessly produce. Actions of the monetary authority always take place at the beginning of the period. The amount of general goods that one unit of fiat money can buy in the $\mathrm{CM}$ of period $t$ is denoted by $\phi_{t}$, the inflation rate is defined as $\phi_{t} / \phi_{t+1}-1=\pi_{t+1}$, and the growth rate of fiat money from period $t-1$ to $t$ is $\frac{M_{t}}{M_{t-1}}=\gamma_{t}$. Newly-printed money is distributed as a lump-sum transfer to young buyers. The real value of these transfers is denoted by $\Delta_{t}$. Agents' money holdings are denoted as $m_{t}$.

The fiscal authority has to finance some spending $g_{t}$ in each period, and can do so by levying lump-sum, per capita taxes $T_{t}$ (raised on young buyers as well as sellers) or by issuing one-period bonds. If the government issues bonds, they are sold for the market-clearing price $p_{b, t}$ and redeemed for one unit of fiat money in the next period. This gives rise to the following government budget constraint:

$$
\phi_{t} p_{b, t} B_{t}+2 N_{t} T_{t}=\phi_{t} B_{t-1}+g_{t}
$$

It is assumed that the government exogenously decides whether to finance its expenditures through debt or taxes. Specifically, I will assume in some sections that the supply of bonds is either zero or strictly positive in all periods. I define the net real lump-sum tax to agents as $\tau_{t}=T_{t}-\Delta_{t} \cdot \mathcal{B}_{t}=\phi B_{t}$ denotes the real amount of bonds. I assume that the government targets some amount of real bonds $\mathcal{B}_{t}$, and issues whatever amount of nominal bonds is required to reach the target given the price level ${ }^{7}$.

There is also an endowment of risky assets with aggregate value $A_{t}$ available in the economy. For simplicity, I will assume that the sellers are endowed with the risky assets at the beginning of the $\mathrm{CM}$ of each period. These risky assets are perfectly divisible. In the following period, the assets pay a high return $\kappa^{H}$ with probability $\chi$ and a low return $\kappa^{L}$ with probability $1-\chi$. The return is an aggregate shock; i.e., when a return is realized in a given period, it is the same for all the assets in the economy. Thus, there is no private information about the return on an asset.

\footnotetext{
${ }^{7}$ This implies that the fiscal authority finances a fixed share of its expenditure through debt. This policy also implies a fixed bonds-to-money ratio. For constant inflation rates, this policy requires a constant bond growth rate.
} 
After the realization of the shock, the assets pay out the real return and cease to exist; i.e., they are replaced by a new set of assets that is independent of the old set in each period. $p_{a, t}$ denotes the price of these risky assets.

These assets are intended to represent the aggregate stock market; i.e., $A_{t}$ represents the unconstrained value of all outstanding equities in period $t$. In other words, $A_{t}$ is the universe of risky investments in the world, and thus already perfectly diversified.

In DM meetings, buyers want to acquire special goods from sellers. Because agents cannot commit to future payments, buyers have to reimburse sellers instantly for the special goods. I assume that sellers cannot distinguish counterfeited bonds or risky assets from real ones during the DM, which means they will only accept fiat money ${ }^{8}$.

\subsection{Real interest rates}

As I want to look at the correlation between asset prices and real interest rates later in the model, it is important to define the real interest rate. I consider

$$
1+r^{n}=\frac{1}{\beta}
$$

to be the natural real interest rate. $r^{n}$ is a benchmark that is given purely by agents' preferences. The actual real interest rate in the model is given by

$$
1+r_{t}=\frac{1}{p_{b, t}} \frac{\phi_{t+1}}{\phi_{t}} .
$$

At $p_{b, t}=\frac{\beta}{1+\pi_{t+1}}, r_{t}=r^{n}$. I therefore define $p_{b}^{*} \equiv \frac{\beta}{1+\pi_{t+1}}$ and call it the unconstrained bond price.

\subsection{The buyer's problem}

A buyer has to decide how many goods he wants to produce in the first $\mathrm{CM}$, in order to acquire fiat money, bonds, and risky assets for consumption in the later phases of his life. A buyer's value function when he is young $W^{y}$ is

$$
\begin{aligned}
W^{y}= & \max _{h_{t}^{y}, d_{t}^{y}, m_{t}^{y} \geq 0, a_{t}^{y} \geq 0, b_{t}^{y} \geq 0}-h_{t}^{y}+u\left(q\left(\phi_{t+1} d_{t}^{y}\right)\right)+\beta\left[\chi W^{o}\left(\kappa^{H} a_{t}^{y}, m_{t}^{y}, b_{t}^{y}\right)+(1-\chi) W^{o}\left(\kappa^{L} a_{t}^{y}, m_{t}^{y}, b_{t}^{y}\right)\right] \\
& \text { s.t. } \quad h_{t}^{y}-\tau_{t}=\phi_{t}\left(m_{t}^{y}+d_{t}^{y}+p_{b, t} b_{t}^{y}\right)+p_{a, t} a_{t}^{y} .
\end{aligned}
$$

\footnotetext{
${ }^{8}$ In Appendix A, I relax these assumptions and allow for partially liquid bonds. This does not change the results of the paper qualitatively.
} 
Here, $h_{t}$ denotes the goods produced in the CM, $d_{t}^{y}$ denotes the money holdings that a young buyer plans to take to the DM, $m_{t}^{y}$ denotes the money holdings that he saves for the next period, $a_{t}^{y}$ denotes a buyer's risky asset holdings, and $b_{t}^{y}$ denotes his bond holdings. Note that the DM money and the savings money are quantities of the same object, but I use two different variables for them instead of the sum, which makes it simpler to solve the problem. Note also that all decision variables of the buyer's problem are subject to a nonnegativity constraint. The function $q\left(\phi_{t+1} d_{t}^{y}\right)$ depends on the terms of trade in the DM and will be made explicit later. Finally, $W^{o, b}\left(\kappa_{t+1} a_{t}^{y}, m_{t}^{y}, b_{t}^{y}\right)$ denotes the value function of an old buyer with money holdings $m_{t}^{y}$, risky asset holdings $a_{t}^{y}$, and bond holdings $b_{t}^{y}$, which is simply

$$
\begin{aligned}
& W^{o}\left(\kappa_{t+1} a_{t}^{y}, m_{t}^{y}, b_{t}^{y}\right)=\max _{x_{t+1}^{o}} U\left(x_{t+1}^{o}\right) \\
& \text { s.t. } \quad x_{t+1}^{o}=\kappa_{t+1} a_{t}^{y}+\phi_{t+1} m_{t}^{y}+\phi_{t+1} b_{t}^{y} .
\end{aligned}
$$

Here, $x_{t+1}^{o}$ denotes the CM consumption of an old buyer. The old buyer sells all his assets in the CM and consumes the earnings.

By substituting in the budget constraints and replacing the bond holdings ${ }^{9}$, we can combine the problem into a lifetime value function.

$$
\begin{aligned}
W=\max _{\substack{h_{t}^{y}, d_{t}^{y}, x_{t+1}^{H}, x_{t+1}^{L}, m_{t}^{y} \geq 0, a_{t}^{y} \geq 0}}-h_{t}^{y}+u\left(q\left(\phi_{t+1} d_{t}^{y}\right)\right)+\beta\left[\chi U\left(x_{t+1}^{H}\right)+(1-\chi) U\left(x_{t+1}^{L}\right)\right] \\
\text { s.t. } \quad h_{t}^{y}-\tau_{t}=p_{a, t} a_{t}^{y}+\phi_{t}\left(m_{t}^{y}+d_{t}^{y}\right)+\frac{\phi_{t}}{\phi_{t+1}} p_{b, t}\left(x_{t+1}^{H}-\kappa^{H} a_{t}^{y}-\phi_{t+1} m_{t}^{y}\right) \\
\text { s.t. } h_{t}^{y}-\tau_{t}=p_{a, t} a_{t}^{y}+\phi_{t}\left(m_{t}^{y}+d_{t}^{y}\right)+\frac{\phi_{t}}{\phi_{t+1}} p_{b, t}\left(x_{t+1}^{L}-\kappa^{L} a_{t}^{y}-\phi_{t+1} m_{t}^{y}\right)
\end{aligned}
$$

\subsection{The DM problem}

To find the first-order conditions for the buyer's problem, we need to know the terms of trade in the DM. As stated above, it is assumed that buyers can make take-it-or-leave-it offers to sellers. Furthermore, sellers only accept fiat money because of limited commitment and their inability to recognize counterfeited assets. The buyers' offer has to satisfy the sellers' participation constraint. This gives rise to the following maximization problem:

\footnotetext{
${ }^{9}$ As I will show later, the nonnegativity constraint for bonds never binds in equilibrium, which is why it is best to replace bond holdings in order to combine the value functions.
} 


$$
\begin{array}{ll}
\max _{q_{t}, d_{t}} & u\left(q_{t}\right)-\beta \phi_{t+1} d_{t} \\
\text { s.t. } & -q_{t}+\beta \phi_{t+1} d_{t} \geq 0 .
\end{array}
$$

The sellers' participation constraint will always be binding, so that the solution to this problem is

$$
q_{t}=\beta \phi_{t+1} d_{t}
$$

Now, we can substitute equation (7) in the buyer's lifetime value function.

\section{Equilibrium}

In this section, I will first derive the market clearing conditions for money, bonds and risky assets. Next, I will shut down the supply of risky assets and bonds, respectively, in order to better explain the intuition of the model, and establish some results that are needed for the further analysis. Then, I will derive the equilibrium in an economy where all assets are in positive supply.

\section{Money market clearing}

The money market clearing condition is given by

$$
\phi_{t} M_{t}=N_{t} z_{t}^{y}
$$

Here, $z_{t}^{y}=\phi_{t}\left(m_{t}^{y}+d_{t}^{y}\right)$ is total real demand for fiat money, given by the real balances of young buyers. Sellers acquire no money in the CM. $\phi_{t} M_{t}$ denotes the supply of fiat money.

\section{Steady-state inflation}

In a steady state, the rate of return on money is constant over time and equals

$$
\frac{1}{1+\pi_{t+1}}=\frac{\phi_{t+1}}{\phi_{t}}=\frac{\frac{N_{t+1} z_{t}^{y}}{M_{t+1}}}{\frac{N_{t} z_{t}^{y}}{M_{t}}}=\frac{n}{\gamma} .
$$

Thus, inflation only depends on the growth rates of money and the population in steady state. 


\section{Bond market clearing}

For the bond market to clear, the price of bonds has to adjust such that agents are willing to hold all bonds. The demand for bonds $b_{t}^{y}$ by buyers is given by:

$$
b_{t}^{y}=\frac{x_{t+1}^{H}-\kappa^{H} a_{t}^{y}-\phi_{t+1} m_{t}^{y}}{\phi_{t+1}}
$$

This can be seen directly in the budget constraint on the value function for old buyers. Since only young buyers demand bonds, total demand for bonds by buyers is given by $N_{t} b_{t}^{y}$.

Sellers will only hold bonds if there is no cost to hold them. This means that sellers only hold bonds if $p_{b, t} \leq \frac{\beta}{1+\pi_{t+1}}=p_{b}^{*}$. However, if $p_{b, t}<p_{b}^{*}$, sellers want to hold an infinite amount of bonds. Since the supply of bonds is finite, the price of bonds will be driven up until $p_{b, t}=p_{b}^{*}$. This creates a lower bound on the price of bonds. At $p_{b}^{*}$, sellers are indifferent about holding bonds, and thus willing to hold any quantity that is left on the market. The amount of bonds held by an individual seller is denoted as $b_{t}^{s}$, so that the total demand for bonds by sellers is $N_{t} b_{t}^{s}$. Now, we can add up the total demand for bonds to determine the market clearing condition:

$$
x_{t+1}^{o}-\kappa_{t+1} a_{t}^{y}-\phi_{t+1} m_{t}^{y}+\phi_{t+1} b_{t}^{s}=\frac{\phi_{t+1} B_{t}}{N_{t}}
$$

with $b_{t}^{s}=0$ if $p_{b, t}>\frac{\beta}{1+\pi_{t+1}}$, and $b_{t}^{s}=\frac{B_{t}}{N_{t}}-\frac{x_{t+1}^{o}-\kappa_{t+1} a_{t}^{y}-\phi_{t+1} m_{t}^{y}}{\phi_{t+1}}$ otherwise.

\section{Asset market clearing}

There exists also an unconstrained price of the risky assets, which is the price at which a riskneutral agent is indifferent to holding these assets. This is the case if the price of the asset exactly equals its discounted expected return, so that

$$
p_{a, t}=\beta\left(\chi \kappa^{H}+(1-\chi) \kappa^{L}\right)
$$

For the remainder of this paper, I will assume that $1=\beta\left(\chi \kappa^{H}+(1-\chi) \kappa^{L}\right)$. This normalizes the unconstrained price of the risky asset to 1 , so whenever a price $p_{a, t}>1$ is observed, the asset is traded above its unconstrained value. Note that this also implies $\kappa^{H} \geq \frac{1}{\beta}$ and $\kappa^{L} \leq \frac{1}{\beta}$.

At the unconstrained price $p_{a, t}=1$, a seller is indifferent between holding the asset and selling it. Thus whenever the assets are priced at their unconstrained value, sellers absorb any risky assets that are not demanded by buyers. At $p_{a_{t}}>1$, sellers strictly prefer to sell the assets, and this implies that to observe such prices, all risky assets must be held by buyers. 
Asset holdings of buyers are given by $a_{t}^{y}$. Since I normalized the expected return on a risky asset to $\frac{1}{\beta}$, sellers are willing to hold any amount of risky assets at the price $p_{a, t}=1$. At any price lower than that, sellers would demand an infinite amount of the assets, thus pushing up the price. Therefore, $p_{a, t}=1$ is the lower bound for the asset price. At any price higher than that, sellers are not willing to hold any risky assets. Thus, market clearing for risky assets is given by

$$
\begin{gathered}
\frac{A_{t}}{N_{t}}=a_{t}^{y}+a_{t}^{s} \\
\text { with } a_{t}^{s}=0 \text { if } p_{a, t}>1 \text {, and } a_{t}^{s}=\frac{A_{t}}{N_{t}}-a_{t}^{y} \text { otherwise. }
\end{gathered}
$$

Buyers are only willing to hold risky assets if bonds are priced above their unconstrained price $p_{b}^{*}$, as otherwise bonds and risky assets have the same rate of return. Once the price of bonds increases above $p_{b}^{*}$, the ensuing demand for risky assets can be interpreted as a portfolio rebalancing effect.

\subsection{Equilibrium without risky assets}

In this section, I will assume that there is no risky asset supply, i.e., $A_{t}=0 \forall t$. This means that agents can only use bonds or fiat money to save. Without risky assets, maximizing the value function from equation (6) gives the following three equilibrium conditions ${ }^{10}$ :

$$
\begin{aligned}
d_{t}^{y}: & 1=\beta \frac{\phi_{t+1}}{\phi_{t}} u^{\prime}\left(\beta \phi_{t+1} d_{t}^{y}\right) \\
m_{t}^{y}: & 1 \geq p_{b, t} \\
x_{t+1}^{o}: & 1=\frac{\beta}{p_{b, t}} \frac{\phi_{t+1}}{\phi_{t}} U^{\prime}\left(x_{t+1}^{o}\right) .
\end{aligned}
$$

The equilibrium condition for DM money is the standard result from Lagos and Wright (2005) and captures the trade-off between consumption and the inflation tax. The equilibrium condition for money as a means of saving shows that agents only use it if the bond price equals 1 . The equilibrium condition on consumption for an old buyer yields a pricing formula for bonds that says that the bond price depends on inflation, and on a stochastic discount factor that consists of the actual discount factor $\beta$ and the marginal utility of old-age consumption ${ }^{11}$.

\footnotetext{
${ }^{10}$ Note that without risky assets, there is no uncertainty about the amount of funds an old buyer will have, and thus the two budget constraints from equation (6) coincide.

${ }^{11}$ By defining the stochastic discount factor (SDF) as $\Lambda_{t} \equiv \beta U^{\prime}\left(x_{t+1}^{o}\right)$, one can write the price of nominal bonds as a function of the SDF and inflation only, as is standard practice in finance. All price changes in this model occur through changes in the SDF, but because the SDF is an endogenous variable, I will not use this notation in the remainder of the paper.
} 
Without risky assets, the market clearing condition for bonds simplifies to:

$$
\begin{gathered}
x_{t+1}^{o}-\phi_{t+1} m_{t}^{y}+\phi_{t+1} b_{t}^{s}=\frac{\phi_{t+1} B_{t}}{N_{t}} \\
\text { with } b_{t}^{s}=0 \quad \text { if } p_{b, t}>\frac{\beta}{1+\pi_{t+1}} \text {, and } b_{t}^{s}=\left(\frac{B_{t}}{N_{t}}+m_{t}^{y}-\frac{x_{t+1}^{o}}{\phi_{t+1}}\right) \text { otherwise. }
\end{gathered}
$$

Now we can define an equilibrium in the economy without risky assets:

Definition 1. An equilibrium in the model without risky assets is a sequence of prices $p_{b, t}$, and quantities $m_{t}^{y}, d_{t}^{y}, x_{t}^{o}$, and $b_{t}^{s}$, that simultaneously solve the equations (13) and (15), as well as the inequalities (14) and (16) and the corresponding complementary slackness conditions $\forall t$.

As can easily be seen in equation (13), the real balances that are chosen by young buyers only depend on the inflation rate that is prevalent in the economy. Old buyers' CM consumption, however, also depends on the price of bonds and thus also on the bond market clearing.

Equation (16) shows that an increase in the supply of bonds $B_{t}$ has to be offset by an increase in $x_{t+1}^{o}$ if $1>p_{b, t}>\frac{\beta}{1+\pi_{t+1}}$. Equation (15) shows that $x_{t+1}^{o}$ is decreasing in the price of bonds. Thus, an increase in the supply of bonds will result in a decrease in the price of bonds. This mechanism is at work until the supply of bonds is high enough for the bond price to fall to $p_{b}^{*}$. From that point onward, a further increase in the supply of bonds will only lead to an increase in $b_{t}^{s}$. I define the corresponding minimal amount of bonds required to reach $p_{b}^{*}$ as $\mathcal{B}^{*}$. From equation (15), it can also be seen that old agents consume the efficient quantity of CM goods if bonds are priced at $p_{b}^{*}$, which means that if the supply of bonds is at least $\mathcal{B}^{*}, \mathrm{CM}$ consumption is efficient. While an increase in the supply of bonds leads to a decrease in the price of bonds if that price is not yet at the lower bound, a decrease in the supply of bonds leads to an increase in the price of bonds. From equation (14), the price of bonds is also bounded above, namely by $p_{b, t}=1$. This is because at that price, holding bonds and fiat money is equally costly. Since fiat money and bonds are equally suitable savings instruments as long as their prices are equal, agents are never willing to pay a higher price for bonds than this. Instead, they would start using fiat money to save if the supply of bonds is not high enough for the bond market to clear at a price $p_{b, t}=1$. I will denote the maximal amount of bonds that leads to a bond price of $p_{b, t}=1$ as $\underline{\mathcal{B}}$. This upper bound in bond prices corresponds to a lower bound in the bond interest rate, i.e., the zero lower bound.

Note that at the Friedman rule $\left(1+\pi_{t+1}=\beta\right)$, the upper and lower bound of the bond price collapse into one, leaving only $p_{b, t}=1$ as a possibility.

Figure 2 shows the bond price as a function of the supply of bonds for a given inflation rate. between $\underline{\mathcal{B}}$ and $\mathcal{B}^{*}$, the price of bonds decreases with increases in the supply of bonds, while the bond price is equal to its upper (lower) bound if supply is lower than $\underline{\mathcal{B}}$ (higher than $\mathcal{B}^{*}$ ). If 


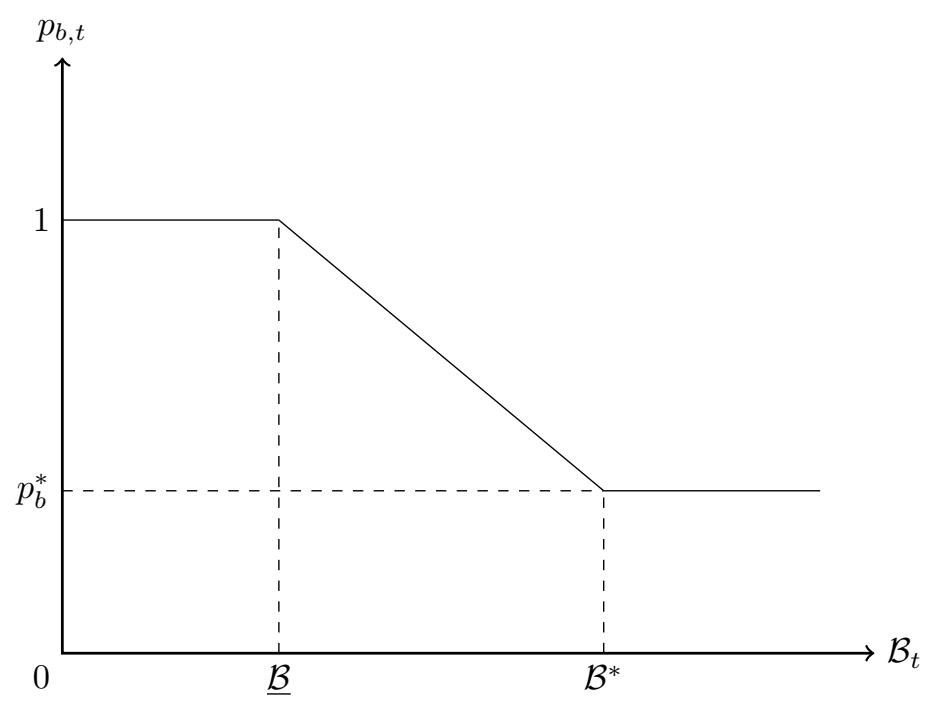

Figure 2: Bond price as a function of supply.

inflation decreases, $\underline{\mathcal{B}}$ shifts to the right while $p_{b}^{*}$ increases, meaning that the range where bond prices change after changes in supply becomes smaller.

As just shown, the model is relatively simple if the risky asset supply is shut down. However, a zero lower bound can occur even in this simplified version of the model. Besides from demonstrating the possibility of a zero lower bound, the main point of this section was to derive the upper and lower bound on bond prices as well as the corresponding bond supplies $\underline{\mathcal{B}}$ and $\mathcal{B}^{*}$, as these are also relevant in the full model. In the next section, I want to analyze the equilibrium of an economy with risky assets but without bonds, in order to, once again, present some intuition that is helpful for understanding the full model, and to define some important thresholds. After that, I will analyze the equilibrium in the full model with both bonds and risky assets present.

\subsection{Equilibrium without bonds}

In this section, I assume a positive supply of risky assets, but no supply of bonds, i.e., $\mathcal{B}_{t}=0 \forall t$. This means that buyers can only use fiat money or risky assets to save, and that the government finances all expenses through taxes.

Without bonds, maximizing the value function of buyers ${ }^{12}$ yields the following four equilibrium

\footnotetext{
${ }^{12}$ To solve this problem, the lifetime value function from equation (6) cannot be used, because it was derived by substituting out bonds. Instead, the value functions of young and old buyers can be combined by substituting out asset holdings, because buyers always hold a positive amount of risky assets in this version of the model as long as inflation is not at the Friedman rule.
} 
conditions:

$$
\begin{aligned}
1 & =\beta \frac{\phi_{t+1}}{\phi_{t}} u^{\prime}\left(\beta \phi_{t+1} d_{t}^{y}\right) \\
\frac{1}{\beta} \frac{\phi_{t}}{\phi_{t+1}} & \geq \chi U^{\prime}\left(x_{t+1}^{H}\right)+(1-\chi) U^{\prime}\left(x_{t+1}^{L}\right) \\
\frac{p_{a, t}}{\beta} & =\kappa^{H} \chi U^{\prime}\left(x_{t+1}^{H}\right)+\kappa^{L}(1-\chi) U^{\prime}\left(x_{t+1}^{L}\right) \\
\phi_{t+1} m_{t}^{y} & =\frac{\kappa^{L} x_{t+1}^{H}-\kappa^{H} x_{t+1}^{L}}{\kappa^{L}-\kappa^{H}} .
\end{aligned}
$$

As in the previous section, the choice of DM money holdings is independent of all other endogenous variables and determined entirely by equation (17). Equation (18) is related to the use of money as a means of savings. If it is slack, money holdings are zero, and thus equation (20) simplifies to $\kappa^{L} x_{t+1}^{H}=\kappa^{H} x_{t+1}^{L}$, which jointly with equation (19) determines consumption levels in $t+1$ in that case. If, however, equation (18) holds at equality, consumption levels in $t+1$ are jointly determined by equations (18) and (19), and then equation (20) solely determines the amount of money holdings used for savings.

The asset market clearing is as follows if there is no bond supply:

$$
\frac{A_{t}}{N_{t}}=\frac{x_{t+1}^{H}-\phi_{t+1} m_{t}^{y}}{\kappa^{H}}+a_{t}^{s}
$$

with $a_{t}^{s}=0$ if $p_{a, t}>1$, and $a_{t}^{s}=\frac{A_{t}}{N_{t}}-\frac{x_{t+1}^{H}-\phi_{t+1} m_{t}^{y}}{\kappa^{H}}$ otherwise.

Now we can define an equilibrium in the economy without risky assets:

Definition 2. An equilibrium in the model without bonds is a sequence of prices $p_{a, t}$, and quantities $m_{t}^{y}, d_{t}^{y}, x_{t}^{H}, x_{t}^{L}$, and $a_{t}^{s}$, that simultaneously solve the equations (17), (19), and (20), as well as the inequalities (18) and (21) and the corresponding complementary slackness conditions $\forall t$.

Equation (21) shows that an increase in the supply of assets leads to either an increase in $x_{t+1}^{o}$ or a decrease in money savings $m_{t}^{y}$ as long as $p_{a, t}>1$. It can be seen directly from equation (19) that an increase in CM consumption has to lead to a decrease in the asset price $p_{a, t} \cdot m_{t}^{y}$ is increasing in the price of the risky assets $p_{a, t}$, so that a decrease in money savings also forces the asset price to go down. Therefore, an increase in the asset supply unambiguously leads to a decrease in asset prices, and vice versa. However, if the price hits the lower bound, a further increase in asset supply does not have an effect on prices, as the sellers absorb any additional risky assets at a price $p_{a, t}=1$. Thus, I denote the corresponding quantity of assets that is at least required to reach $p_{a, t}=1$ as $A^{*}$. 
At $\bar{p}_{a} \equiv\left(1+\pi_{t+1}\right)\left(\chi \kappa^{H}+(1-\chi) \kappa^{L}\right)=\frac{1+\pi_{t+1}}{\beta}$, expected returns on risky assets and fiat money are equal. Since buyers are risk-averse, they will strictly prefer to save with money at this price, and thus $x_{t+1}^{H}=x_{t+1}^{L}$ and $a_{t}^{y}=0$ at $\bar{p}_{a}$. For any $A_{t}>0, \bar{p}_{a}$ cannot occur in equilibrium.

If $p_{a, t}$ is sufficiently small, equation (18) cannot hold at equality for nonnegative money balances. For some price $p_{a, t}$, equation (18) holds at equality with $m_{t}^{y}=0$. I will label this price as $\tilde{p}_{a}$. For any $p_{a} \leq \tilde{p}_{a}$, buyers choose not to hold any money balances for savings, while they hold positive money balances for any $p_{a}>\tilde{p}_{a}$. I denote the corresponding quantity of assets that leads to $\tilde{p}_{a}$ as $\tilde{A}$. Note that $\tilde{p}_{a} \lessgtr 1$ in principle, so that it is not clear whether $\tilde{p}_{a}$ is a feasible price. If $\tilde{p}_{a}<1$, buyers use money to save even if the asset price is unconstrained.

Higher inflation and less variance $\kappa^{H}-\kappa^{L}$ both make it more likely that $\tilde{p}_{a}>1$. At some inflation rate $\tilde{\pi}$, equation (18) holds at equality for $m_{t}^{y}=0$ and $p_{a, t}=1$. At any inflation rate lower (higher) than $\tilde{\pi}, \tilde{p}_{a}<1\left(\tilde{p}_{a}>1\right)$. In other words, this means that there is some inflation rate at which buyers are exactly indifferent between using and not using money to save if the asset price is at its unconstrained value. For inflation levels below $\tilde{\pi}, A^{*}$ is a function of inflation, while it is determined entirely by preference parameters if inflation is above $\tilde{\pi}$. This is depicted in Figure 3. To the left of the crossing with the blue dashed line, the red line symbolizes the supply of risky assets required to reach a risky asset price that would make buyers indifferent to using money to save if there were no sellers, i.e., if $p_{a}<1$ were feasible.

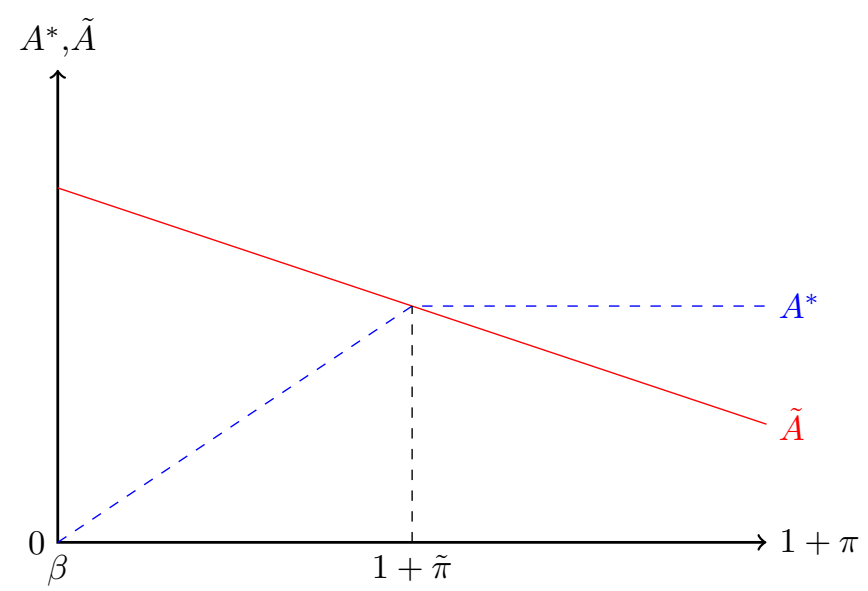

Figure 3: $A^{*}$ and $\tilde{A}$ as a function of inflation.

Figure 4 shows the price of assets as a function of asset supply for relatively low inflation rates, i.e., $\pi<\tilde{\pi}$. In this case, buyers hold a savings portfolio consisting of assets and money for all possible equilibrium realizations of asset prices. The price of assets is downward sloping in the 


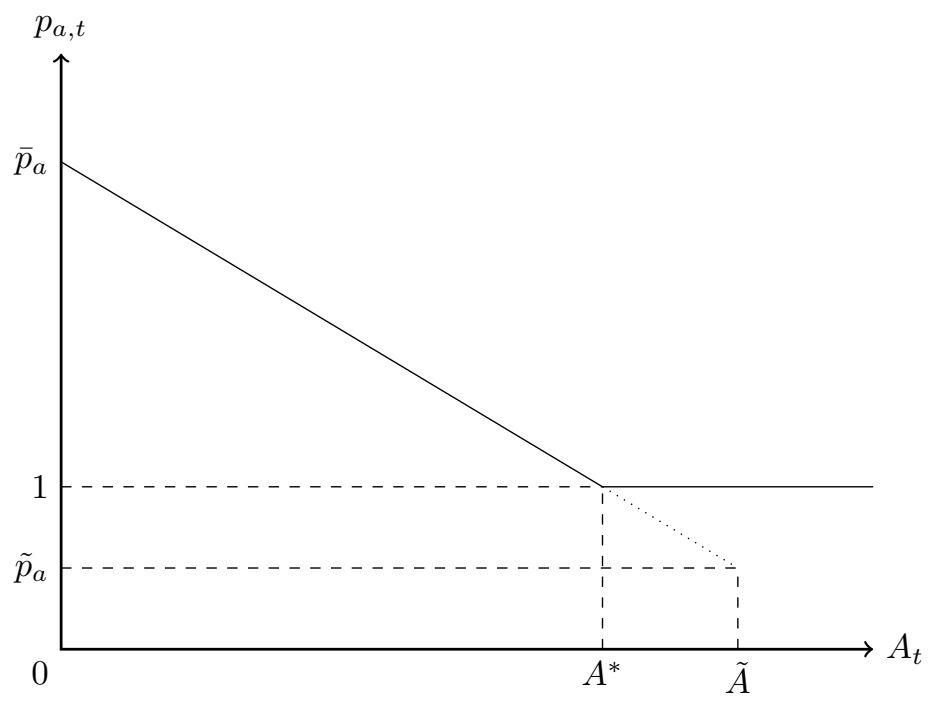

Figure 4: Asset price as a function of supply for relatively high inflation rates.

asset supply until $p_{a, t}=1$. The dotted line in Figure 4 depicts how the asset prices would develop for $A_{t}>A^{*}$ if there were no sellers.

Figure 5 shows the price of assets as a function of the asset supply for $\pi>\tilde{\pi}$. High inflation means that $\tilde{p}_{a}>1$, so that at $\tilde{A}$, the slope changes as agents stop using fiat money to save for any $A_{t}>\tilde{A}$. If inflation decreases, both $\bar{p}_{a}$ and $\tilde{p}_{a}$ decrease, as money becomes relatively more attractive as a means of saving, causing agents to start using money to save and stop demanding risky assets at lower prices.

Similar to the previous section on an economy without risky assets, this section mainly serves the purpose of illustrating some intuition about the tradoffs buyers face when risky assets are available as a means of saving, and defining some important risky asset prices and quantities. The next section presents the equilibrium in the full model where buyers can use all three assets to save.

\subsection{Equilibrium with positive supply of all assets}

With a positive supply of both bonds and risky assets, maximizing the lifetime value function of buyers from equation (6) yields the following equilibrium conditions: 


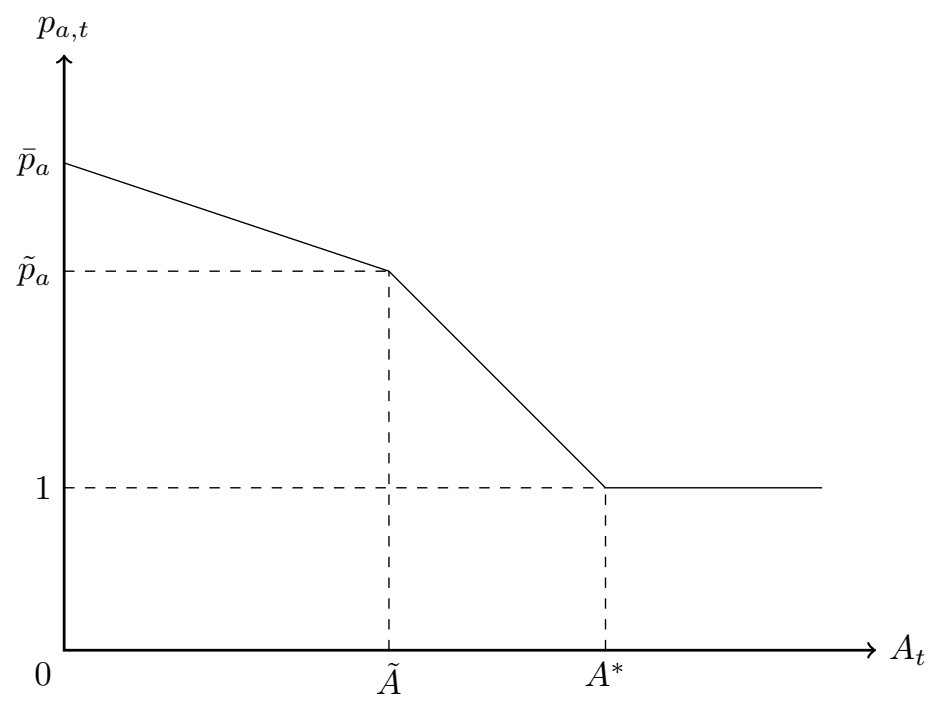

Figure 5: Asset price as a function of supply for relatively high inflation rates.

$$
\begin{aligned}
1 & =\beta \frac{\phi_{t+1}}{\phi_{t}} u^{\prime}\left(\beta \phi_{t+1} d_{t}^{y}\right) \\
1 & \geq p_{b, t} \\
\frac{\phi_{t}}{\phi_{t+1}} \frac{p_{b, t}}{\beta} & =\chi U^{\prime}\left(x_{t+1}^{H}\right)+(1-\chi) U^{\prime}\left(x_{t+1}^{L}\right) \\
\frac{p_{a, t}}{\beta} & \geq \kappa^{H} \chi U^{\prime}\left(x_{t+1}^{H}\right)+\kappa^{L}(1-\chi) U^{\prime}\left(x_{t+1}^{L}\right) \\
x_{t+1}^{H}-x_{t+1}^{L} & =a_{t}^{y}\left(\kappa^{H}-\kappa^{L}\right) .
\end{aligned}
$$

Equation (22) shows that the choice of money holdings used in DM meetings is independent of other decisions and depends only on the terms of trade and inflation rates. Condition (23) shows that agents only want to save with money if the price of bonds equals one. Equation (24) sets the cost of acquiring and holding bonds equal to the benefit of holding more bonds, namely more consumption in both the high and the low state. If condition (25) holds with equality, agents acquire risky assets such that the cost of acquiring them is equal to the benefit that they can derive from them. If asset prices are too high, condition (25) will not hold at equality, and agents thus acquire no risky assets. Finally, equation (26) states that any difference in consumption levels in the second period is caused by asset holdings. Consequently, consumption in the low and the high state will be equal if the return on the asset is not risky or if agents do not hold any risky assets.

In the following, I will define the equilibrium for the model that has all the assets:

Definition 3. An equilibrium in the full model is a sequence of prices $p_{b, t}, p_{a, t}$, and quantities $d_{t}^{y}$, $x_{t+1}^{H}, x_{t+1}^{L}, m_{t}^{y}, a_{t}^{y}, b_{t}^{s}$, and $a_{t}^{s}$, that simultaneously solve the equations (22), (24), (26), and the 
following inequalities with complementary slackness conditions: (23), (25), (10), and (12) $\forall t$.

The equilibrium conditions give rise to a number of different regions in the parameter space for which the resulting equilibrium differs. In the following, I will characterize the different possible equilibria. One aspect in the characterization will be the correlation between asset prices and the real interest rate, which is helpful in linking the equilibrium regions with the observed data. Note that expected dividends, given by $\kappa^{H}$ and $\kappa^{L}$, are constant in the model, which means that asset price changes are equivalent to changes in the dividend-price ratio. For a given inflation rate, the selection of an equilibrium region depends on the supply of risky assets $A_{t}$ and the real bond supply $\mathcal{B}_{t}$. Figures 6 and 7 depict the equilibrium regions for high and low inflation rates, respectively.

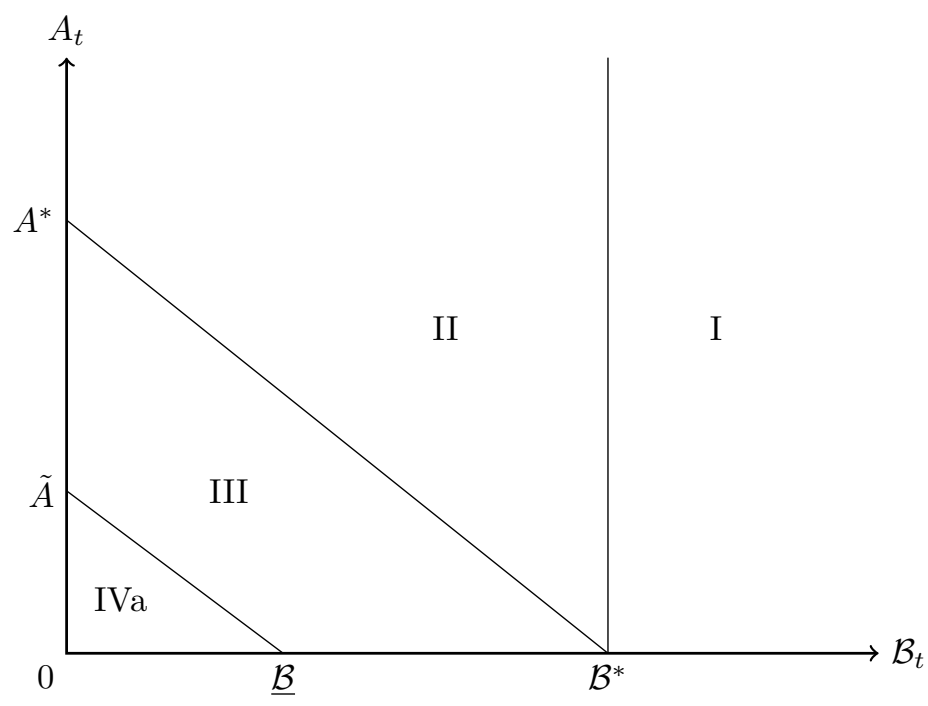

Figure 6: Equilibrium regions for $\tilde{p}_{a}>1$.

Proposition 1. If the supply of government bonds exceeds $\mathcal{B}^{*}$, buyers will only hold bonds, while sellers hold all the risky assets and the remaining government bonds. Risky asset prices and real interest rates are both constant.

If the supply of government bonds is at least $\mathcal{B}^{*}$, the bonds will be priced at their lower bound, i.e., $p_{b, t}=p_{b}^{*}$. This means that a bond pays the same expected return as a risky asset, but since buyers are risk-averse, they will only hold the riskless asset, i.e., the bond. It can be shown that at this bond price, condition (25) can only hold at equality for $x_{t+1}^{H}=x_{t+1}^{L}$, which is only possible for $a_{t}^{y}=0$ according to equation (26), thus proving the proposition.

I will denote the parameter region for which Proposition 1 holds as region I. It is defined by $p_{b, t}=p_{b}^{*}$, while $p_{a, t}=1$. In this case, $r_{t}=r^{n} \forall t$, so that both the price of risky assets as well as 


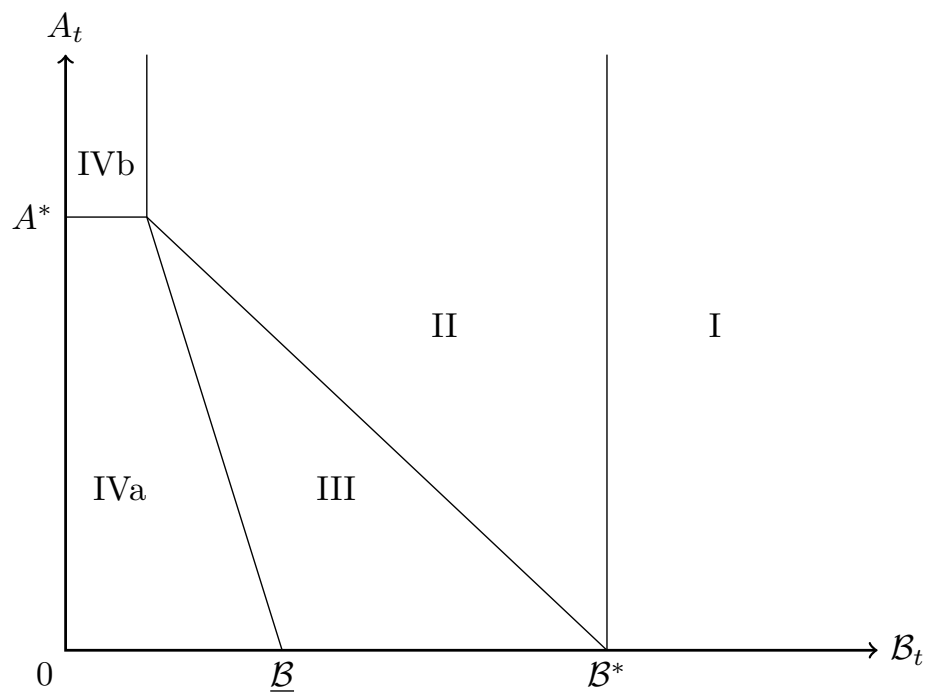

Figure 7: Equilibrium regions for $\tilde{p}_{a} \leq 1$.

the real interest rate are constant over time. As both of these variables are time-varying in reality, equilibrium region I does not seem to be prevalent in today's economies.

Proposition 2. If $\mathcal{B}_{t}<\mathcal{B}^{*}$, but the combined supply of $\mathcal{B}_{t}$ and $A_{t}$ is sufficiently large, buyers will hold all the bonds and some risky assets. Sellers hold the remaining risky assets. There is a risk premium paid on risky assets compared to government bonds, but risky assets are still priced at their unconstrained value. Real interest rates and asset prices are uncorrelated.

Once the price of bonds is lifted above the lower bound, the expected return on bonds becomes lower than the expected return on a risky asset priced at its unconstrained value. Buyers can thus increase their utility by holding some risky assets. The amount of risky assets they are willing to hold depends on their risk aversion. Whenever $p_{b, t}>p_{b}^{*}$ and $p_{a, t}=1$, for condition (25) to be a strict inequality, $x_{t+1}^{H}>x_{t+1}^{L}$ is required. However, this leads to a contradiction with equation (26), as $x_{t+1}^{H}>x_{t+1}^{L}$ is only possible for $a_{t}^{y}>0$, which in turn requires equation (25) to hold at equality. This shows that buyers will always hold some risky assets in this case. Note that in this region, we will typically observe $x^{H}>x^{*}>x^{L} . r_{t}<r^{n}$ in this region and varies with inflation and the real bond supply. However, because the price of risky assets is always equal to 1 , real interest rates and asset prices are uncorrelated.

I will denote the parameter region for which Proposition 2 holds as region II. It is defined by $1>p_{b, t}>p_{b}^{*}$, while $p_{a, t}=1$.

Proposition 3. If the combined supply of bonds and risky assets is scarce, the price of both assets 
will be above its lower bound, and buyers will hold the entire supply of both assets. Real interest rates and asset prices are negatively correlated.

In region II, buyers demand some risky assets. The lower the buyer's risk aversion and the higher the price of government bonds, the more risky assets they demand. At some point, demand exceeds supply at the unconstrained price, thus raising the price of risky assets above its unconstrained level. This discourages sellers from holding risky assets. Once risky assets and bonds are both priced above their unconstrained value, their prices are correlated, which in turn means that real interest rates and asset prices are negatively correlated.

I will denote the parameter region for which Proposition 3 holds as region III. It is defined by $1>p_{b, t}>p_{b}^{*}$, while $p_{a, t}>1$, so that both assets are priced above their unconstrained value. This region can be considered an asset shortage equilibrium.

Proposition 4. If the combined supply of bonds and risky assets is severely scarce, bonds will yield the same return as fiat money, and buyers will also use fiat money to save. Real interest rates and asset prices can be negatively correlated or uncorrelated.

Once the bond price is driven up to $p_{b, t}=1$, buyers will cease to demand more bonds or risky assets, but will start to save with fiat money instead. Depending on the risk aversion parameters and the supply of risky assets, the price of risky assets can be at its unconstrained value, or above it. In an economy without risky assets, $p_{b, t}=1$ if $\mathcal{B}_{t} \leq \underline{\mathcal{B}}$. With risky assets available, the amount of bonds required to step away from the zero lower bound becomes smaller as buyers also use risky assets to save.

I will denote the parameter region for which Proposition 4 holds as region IV. It is defined by $p_{b, t}=1$ and can therefore be considered a zero lower bound equilibrium. Note that it can exist with either $p_{a, t}>1$ or $p_{a, t}=1$, depending on the inflation rate. I denote the parameter space where we simultaneously observe an asset shortage and a zero lower bound as region IVa, while a zero lower bound without an asset shortage is denoted as a IVb equilibrium. In region IVa, asset prices and real interest rates are negatively correlated (nominal interest rates are constant at zero, but an increase in inflation makes real assets relatively more attractive to hold and thus increases their price). In region IVb, real interest rates and asset prices are uncorrelated, as assets are priced at their unconstrained value regardless of the inflation rate.

A IVb equilibrium can only exist if buyers use money to save even when they are satiated with risky assets. Thus, this equilibrium exists only if $\pi<\tilde{\pi}$ and thus $\tilde{p}_{a} \leq 1$. This situation is depicted 
in Figure 7.

\subsection{Risk premium}

The risk premium is typically defined as the difference in expected return between a risky and a safe asset that both deliver the same services. Thus, the difference in expected return between the risky asset and the government bond is a natural candidate for the risk premium in this model, which I therefore define as

$$
\mathcal{R}_{t}=\frac{1}{\beta} / p_{a, t}-\frac{\phi_{t+1}}{\phi_{t}} / p_{b, t}
$$

Note that if both assets are priced at their unconstrained value, i.e., in region I, $\mathcal{R}_{t}=0$. However, the risk premium measures the difference in expected returns that makes a single agent indifferent between the two assets. Since buyers are not willing to hold risky assets in region I, the risk premium cannot be measured in that region. In all other regions, however, buyers hold a positive amount of both assets and are thus indifferent between the two at the margin. Interestingly, $\mathcal{R}_{t}$ is not a constant: In region II, $p_{a, t}=1$ everywhere, while $1>p_{b, t}>\beta \frac{\phi_{t+1}}{\phi_{t}}$. Thus, the risk premium can also vary within these bounds on $p_{b, t}$. In region III, $\mathcal{R}_{t}$ can increase or decrease depending on whether $p_{a, t}$ or $p_{b, t}$ increase faster, but in region IVa, the risk premium decreases again because $p_{b, t}=1$, whereas $p_{a, t}$ increases the lower the risky asset supply becomes within region IVa. In region $\mathrm{IVb}, p_{b, t}=p_{a, t}=1$, so the risk premium is constant at $\mathcal{R}_{t}=\frac{1}{\beta}-\frac{\phi_{t+1}}{\phi_{t}}$.

\subsection{Comparative statics}

In this subsection, I want to analyze the comparative statics of inflation, the supply of both risky assets and bonds, as well as the riskiness of the assets in all equilibrium regions.

\subsubsection{Inflation}

From equation (22), it is obvious that inflation reduces real money holdings brought to the DM $\phi_{t} d_{t}^{y}$ and thus also the DM consumption of young agents. Since this is true for all regions, it is clear that inflation always has some negative effects. As it turns out, inflation does not have positive effects on the CM consumption either, thus making the Friedman rule optimal.

In region I, because the bond price compensates fully for inflation, an increase in inflation leads to a decrease in bond prices in this region, without affecting second-period consumption or other real variables. In region II, the bond price does not fully compensate for inflation because of the scarcity of bonds. Without scarcity, the bond price would drop exactly as much as inflation increases, allowing buyers to obtain the same level of consumption after the change, just like in 
region 1. However, to obtain the same level of consumption as before the increase in inflation, buyers would need to hold more bonds, which puts upward pressure on the bond price. As a result, the bond price drops somewhat (at the previous bond price, agents would demand fewer bonds than before), but not enough to fully compensate for inflation. Asset prices stay at their lower bound in this region, because there is no asset scarcity. This means that an increase in inflation leads to buyers holding more assets (assets become relatively more attractive, because the difference in returns increases), and thus also the difference $x_{t+1}^{H}-x_{t+1}^{L}$ increases. All in all, buyers are worse off.

In region III, both assets are scarce, and thus buyers hold all bonds and all risky assets. The effect of an increase in inflation on bonds is thus similar to what happens in region II, but since buyers cannot compensate by holding more risky assets now, the price of risky assets also increases. Thus, buyers have to work more to purchase the assets, and they obtain less consumption in both states, because the real rate of return on bonds decreases, making them clearly worse off. In region IV, bonds are so scarce that fiat money is a perfect substitute for bonds as a means of saving. Thus, an increase in inflation does not affect bond prices, which remain at $p_{b, t}=1$, meaning that the real return on bonds decreases even more than in regions II and III. Additionally, buyers will reduce their money savings somewhat, because the real return on money also decreases. In region IVb, buyers can substitute money and bonds for risky assets, so that the overall effects are similar to region II, i.e., consumption variance increases, but expected consumption remains constant. In region IVa, buyers would also like to purchase more risky assets, but because they are scarce in this region, they merely drive up asset prices, making the overall effects in this region similar to those in region III. Clearly, buyers are again made worse off by an increase in inflation in region IV.

\subsubsection{Decrease in the supply of risky assets}

In regions I, II, and IVb, such a change has no real effect, as at least some risky assets are held by sellers, and the sellers are indifferent to holding them. In region III, a decrease in the supply of risky assets leads to an increase in the price of risky assets. As this makes bonds relatively more attractive, bond prices also increase. Thus, second-period consumption falls in both states, because less risky assets can be held by buyers, but also the difference $x_{t+1}^{H}-x_{t+1}^{L}$ decreases as $a_{t}^{y}$ falls.

In region IVa, the effect is similar, except that instead of increasing bond prices, money savings increase. This increase reduces the difference $x_{t+1}^{H}-x_{t+1}^{L}$. However, expected consumption also falls somewhat, as buyers are not willing to fully replace the missing assets with money savings 
due to the inflation tax. Thus, buyers are worse off.

\subsubsection{Decrease in the supply of government bonds}

As bonds are not scarce in region I, a marginal decrease in their supply has no real effect. In region II, bonds are scarce, thus a further decrease in supply leads to an increase in the bond price. This makes risky assets relatively more attractive, and since they are not scarce, buyers can easily invest in them as substitutes. Thus, their consumption variance increases, but their expected consumption does not decrease. In region III, similar mechanisms are at play as in region II, but since risky assets are also scarce, buyers cannot hold more of them and instead drive up their price. This makes purchasing the assets more expensive, and drives down CM consumption in both states as fewer assets are available. In region IV, a decrease in bonds has no real effect again, as bonds are already priced at their upper bound, and a further decrease in supply thus only increases money savings.

\subsubsection{Riskiness of the asset}

In general, it is clear that the less risky the asset is, i.e., the smaller $\frac{\kappa^{H}}{\kappa^{L}}$ is, the better risky assets become as a substitute for bonds.

In region I, the riskiness of the asset does not matter as only risk-neutral agents (sellers) are willing to hold them. In region II, less riskiness makes the assets more attractive, thus increasing $a_{t}^{y}$, which lowers pressure on bond prices and thus leads to lower $p_{b, t}$. Agents consume more in the low state and welfare increases. In region III, the greater attractiveness of the assets increases their scarcity, thus increasing asset prices. However, the pressure on bond prices is reduced, which leads to a decrease in bond prices. Overall, agents are better off, because the variance of their consumption decreases. In region IVb, the effects are similar to region 2, but without a change in bond prices. In region IVa, asset prices increase, but welfare still increases as buyers experience less variance in their second-period consumption.

\section{Empirical relevance}

In this section, I first want to relate the findings from Section 3 with the data presented in Section 1.2 , and then I want to give some interpretations for the OLG structure of the model. 


\subsection{Relating the model to the data}

As explained in Section 1.2, a strong correlation between real interest rates and dividend-price ratios can be found in the US data from 1982 to 2007, but this correlation has vanished since. In the model, there is a positive correlation between bond and asset price $^{13}$ in equilibrium regions III and IVa. Because there was no zero lower bound episode prior to the financial crisis, we can conclude that the US economy has been in equilibrium region III until 2007. Since then, the zero lower bound was hit and the correlation between bond and asset prices has vanished. This regime corresponds to equilibrium region IVb. Thus, we are interested in effects that induce a transition from region III to region IVb.

The model offers two possible explanations for a transition from equilibrium region III to IVb. The first one is about the supply of different asset categories. Figures 6 and 7 show how changes in the supply of risky assets and the real bond supply can induce transitions from one equilibrium region to another. Because we are interested in a transition to region IVb, we can focus on 7 . This makes sense, because this figure applies for environments with low inflation, and inflation was relatively low in recent decades. To transition from region III to region IVb, a simultaneous reduction in the supply of safe assets and an increase in the supply of risky assets is required. During and after the financial crisis, many assets that were considered safe (e.g., mortgage-backed securities, European sovereign debt) turned out to be risky in fact. This can be interpreted as changes in the supply of safe and risky assets, and thus is one empirically plausible way to understand the transition.

For the second explanation, we also need the comparative statics. If inflation is relatively low (Figure 7 applies), inflation affects $A^{*}$ (increasing with inflation) and $\underline{\mathcal{B}}$ (decreasing with inflation). This means that all transitions among equilibrium regions II, III, IVa, and IVb could be induced by changes in inflation. For a transition from region III to region IVb, a decrease in inflation is required. This causes an increase in $\underline{\mathcal{B}}$ and a decrease in $A^{*}$, which means that asset supplies that lead to equilibrium region III before the change in inflation can now lie in region IVb. Since inflation rates were indeed lower in the years during and after the financial crisis than before, this explanation is also empirically plausible.

As just explained, the model is able to suggest two empirically plausible explanations as to why the correlation between bond and asset prices vanished after the financial crisis. The first

\footnotetext{
${ }^{13}$ Which is equivalent to a positive correlation between real interest rates and dividend-price ratios.
} 
explanation is a simultaneous increase in the supply of risky assets and a decrease in the supply of safe assets, and the second explanation is a decrease in inflation.

The decrease in inflation after the financial crisis is well documented. According to FRED, the US Annual CPI dropped from almost 4 percent in 2007 to slightly negative territory in 2008. While the CPI steadily increased to about 3.1 percent in 2011, it has never been higher than slightly above 2 percent since.

The changes in asset supply are harder to measure, as it is difficult to define the relevant universe of assets. However, there are various studies that document changes in asset supply supporting the arguments made here. Caballero et al. (2017) show the decrease in interest rates on safe assets and cite a number of papers that report a shortage of safe assets. Covitz et al. (2013) show how the risk spreads of asset-backed securities substantially increased from August 2007 onwards. Beirne and Fratzscher (2013) document the increase in spreads of European sovereign debt during and after the financial crisis. Falato et al. (2018) document a decrease in corporate leverage in recent years, which means that corporations issue less debt. While corporate bonds are not part of the model I presented here, they could be seen as close substitutes to government bonds.

\subsection{Interpretations of the model structure}

The model structure with the two types of agents - buyers and sellers - is standard in the New Monetarism literature that follows Lagos and Wright (2005) and especially Rocheteau and Wright (2005). However, what is special in this paper is that the buyers have a finite lifespan, while the sellers have an infinite lifespan. Therefore, in this section I want to offer two possible interpretations as to how this could be related to reality.

\section{Sellers as firms}

One obvious interpretation is that buyers are households that have a finite lifespan and go through different periods of life, while sellers are firms with an infinite lifetime. In this interpretation, the buyers' first period (when they are young) is their part of life as a member of the labor force, and the second period (when they are old) is their retirement. Here, firms only invest if an opportunity of high returns presents themselves, while households need to invest in any case in order to save for old age. 


\section{Life-cycle interpretation}

If one wants to take the life-cycle considerations of the model a bit more seriously, there is another interpretation of the two types of agents. This version would require some changes in the environment, but it doesn't change any of the results.

In this interpretation, every agent is born as a seller. A seller has the same preferences as in the standard model, but additionally, there is a probability $\delta$ with which he turns into a buyer at the beginning of a period. The buyers' preferences stay unchanged, so once an agent turns into a buyer, he has two periods (three subperiods) left to live. Because buyers can work at linear disutility during their first CM, the sellers' actions are unchanged compared to the standard interpretation of the model. The buyers' decisions are also unchanged, because once an agent becomes a buyer, his decision problem is exactly the same as in the standard interpretation of the model. In this interpretation, being a seller would represent workers who just entered the labor force. Being a young buyer would represent workers who are close to retirement, and being an old buyer would represent retired workers. Within this interpretation, the investment strategies also seem similar to those in the real world: Agents that are still far away from retirement (sellers) mainly care about the expected return when investing, not so much about the risk - and they are only willing to invest when returns are high. Agents who are close to retirement (young buyers) however must have some savings in order to consume when they retire, so they invest even when returns are bad. Finally, retired agents (old buyers) dissave.

\section{Policy}

In this section, I analyze how monetary or fiscal policy can improve market outcomes. In fact, it is easy for the authorities to achieve the first-best: Running the Friedman rule ensures both $q^{*}$ and $x^{*}$. If this is not an option, it is still possible to achieve $x^{*}$ by issuing enough bonds; i.e., enough to reach a real bond supply of $\mathcal{B}^{*}$. However, there might be limits that prevent the implementation of these policies. Regarding the government debt, these limits could be political, as governments have to go through the political process in order to issue more government debt, and there might not be a political consensus to increase the amount of debt, even if it would be welfare increasing. To implement the Friedman rule, the central bank has to be able to raise lump-sum taxes. Since central banks in reality don't have the ability to raise taxes, it might not be possible for them to implement this policy. But even if the central bank is allowed by law to implement lump-sum taxes, there might be a limit to the level of this tax due to incentive-feasibility, as Andolfatto (2013) points out. An earlier paper that argues why the Friedman rule might not be feasible is 
Bewley (1983). Another reason why the Friedman rule can not be implemented by the central bank could be that the long run inflation target is set by someone else, e.g. the government, as is the case in the U.K. The central bank can then only choose how to implement the target, while the level of the inflation target is subject to political debates, and thus much more difficult to change. A similar reasoning is used by Berentsen and Waller (2011).

Therefore, in this section I want to analyze what other policies could be used to improve welfare if, for whatever reason, the monetary and fiscal authorities are not willing or able to run the Friedman rule or to issue $\mathcal{B}^{*}$ government debt. Specifically, I will show that the monetary authority can improve welfare through stabilization policy. But first, I want to quickly discuss the optimal inflation target.

\subsection{Optimal inflation target}

As explained above, the first-best can be achieved by running the Friedman rule, i.e., by setting $1+\pi=\beta$. This ensures that first-best quantities can be consumed even if agents save by using money, thereby making scarcities of bonds or risky assets irrelevant. On top of this, Section 3.5.1 showed that any increase in inflation is welfare-reducing, so if the Friedman rule is not a feasible policy, the inflation target should be set as low as possible. This is true even though the zero lower bound is more likely to occur at low inflation rates, because the zero lower bound is also less harmful if inflation is low. This shows that it is not a good idea to increase inflation targets in order to reduce the probability of hitting the zero lower bound. Even though the policy change achieves this goal, total welfare is reduced.

\subsection{Optimal stabilization policy}

When risky assets are part of the savings portfolio, the old buyers' consumption varies with the return on these assets. Because all other potential savings assets are nominal, the central bank can affect their return. By setting the return on money and bonds high in bad states regarding the risky assets, and low in good states, overall consumption volatility can be reduced, which is welfare-improving. This means that the central bank should keep the money supply and inflation low in bad states, but high in good states.

If we assume a target for the expected inflation rate, the central bank can choose the value of money in the two possible states according to ${ }^{14}$

\footnotetext{
${ }^{14}$ Note that the superscripts $\mathrm{H}$ and L stand for the high and the low value of money, respectively. To implement the policy, the central bank sets a high value of money in periods with low asset return, and a low value of money in periods with high asset return.
} 


$$
\mathbb{E}_{t}\left[\phi_{t+1}\right]=\chi \phi_{t+1}^{L}+(1-\chi) \phi_{t+1}^{H} .
$$

By adopting such a policy, the monetary authority makes bonds and fiat money savings instruments that are negatively correlated with the risky asset. In principle, the monetary authority can always choose values for $\phi_{t+1}^{L}$ and $\phi_{t+1}^{H}$ such that the overall portfolio of buyers becomes risk-free. If the monetary authority cannot raise taxes, $\phi_{t+1}^{H} \leq \phi_{t}$, so full insurance might not be feasible, but reducing the consumption risk is still possible.

The DM choices of buyers are not affected by this policy, as the expected inflation rate during the DM is equal to the long-run inflation rate. For sellers, this means that their CM consumption becomes random, as it now depends on the realization of the inflation rate. However, because sellers are risk-neutral, this does not reduce their welfare ${ }^{15}$.

To make the buyers' portfolio risk-free, the condition

$$
\kappa^{H} a_{t}^{y}+\phi_{t+1}^{L} b_{t}^{y}=\kappa^{L} a_{t}^{y}+\phi_{t+1}^{H} b_{t}^{y}
$$

has to hold, as then buyers obtain the same amount of consumption in both states. If equation (28) is satisfied for the portfolio that the buyers choose to hold, they are indifferent at the margin between the two kinds of assets. Thus, prices will adjust, such that the expected returns on the two assets will be equal, which is given by

$$
\frac{1}{p_{a, t}}=\frac{\beta \mathbb{E}_{t}\left[\phi_{t+1}\right]}{\phi_{t} p_{b, t}}
$$

Implementing the policy such that equation (28) holds is not straightforward, as the buyers' portfolio choice is a function of the central bank's policy. However, the central bank can just select a feasible portfolio and then choose $\phi_{t+1}^{L}$ and $\phi_{t+1}^{H}$ such that equation (28) holds for the chosen portfolio, and buyers will then choose to hold this portfolio if some other conditions are satisfied, where these other conditions depend on the equilibrium region in which the economy finds itself. How exactly this can be done is explained in Appendix B.

If there are no limits to $\phi_{t}^{H}$, the stabilization policy is able to eliminate consumption volatility completely in all equilibrium regions. As this happens without reducing expected consumption, it

\footnotetext{
${ }^{15}$ While the risk-neutrality of the sellers allows for Pareto improvements through stabilization policy in this model, this result does not hold for more general utility functions of sellers. But even then, stabilization policy can make some agents better off, so it can still be a beneficial policy if these agents are particularly important. At the very least, this shows that a countercyclical monetary policy has clear negative effects on some agents in the economy.
} 
is welfare improving. In regions II and IVb, the first-best in terms of CM consumption can even be achieved. This is because risky assets are not scarce in this region, so the central bank can choose a portfolio that simultaneously satisfies (28), and $\kappa^{H} a_{t}^{y}+\phi_{t+1}^{L} b_{t}^{y}=x^{*}$. In regions III and IVa, the first-best is not achievable, because all assets are scarce in these regions.

If the central bank has no access to lump-sum taxes, there is a limit to the spread between $\phi_{t+1}^{L}$ $\phi_{t+1}^{H}$ the central bank can choose. Depending on other parameters, this spread might not be enough to make CM consumption completely risk-free. By setting $\phi_{t+1}^{H}=\phi_{t}$ and $\phi_{t+1}^{L}$ according to equation (27) the policy will still increase welfare by reducing consumption variance in this case.

This analysis shows that reacting to asset return shocks can be welfare improving. Bernanke and Gertler (2001) argue that asset returns should only matter for monetary policy if they affect the inflation rate. That is not the case here, as inflation remains constant as long as the central bank does not change its policy. Still, monetary policy that takes asset returns into account improves welfare, because it allows agents to smooth consumption across different states. This shows that there is a role for stabilization policy when aggregate asset return shocks affect the consumption of savers. Additionally, note that to achieve the optimal stabilization policy, the monetary authority increases inflation when asset returns are high, and lowers inflation when asset returns are low. This also goes against the conventional wisdom that inflation should be countercyclical to prevent the economy from 'overheating' in good times or to 'kickstart' it when it is in a slump. Berentsen and Waller $(2011,2015)$ also find a procyclical policy to be optimal in their model. However, they have underconsumption in good states and overconsumption in bad states without intervention. In my model, there is overconsumption in good states and underconsumption in bad states without intervention. Another difference are the drivers of the different states: In Berentsen and Waller (2011, 2015), different states occur due to preference shocks, not due to asset returns.

\subsection{Quantitative easing}

While quantitative easing is not optimal in this model, the framework still lends itself well to an analysis of the effect of quantitative easing on the welfare of future generations. Quantitative easing, i.e., printing money to buy bonds, is a policy that reduces the real bond supply that is available to agents. As I have shown in this paper, a reduction in real bond supply is bad for the welfare of young buyers. Thus, while quantitative easing might have some positive effects on current output, policymakers should keep in mind that it negatively affects the current young generation, as it makes their savings options worse. 


\section{Conclusion}

This paper shows that, depending on inflation and the supply of risky assets and government bonds, there are equilibrium regions where the prices of risky assets and bonds are positively correlated, and regions where they are uncorrelated. Both a decrease in inflation, and a simultaneous increase in the supply of risky assets and a decrease in the supply of safe assets, are empirically plausible explanations for the changes in the correlation of bond and asset prices that were observed in the U.S. The model shows that, away from the Friedman rule, welfare increases with the amount of government debt up to a certain level, while it remains constant for higher levels of government debt. If it is politically infeasible for the fiscal authority to provide enough government debt, the monetary authority can improve welfare by running a procyclical monetary policy, i.e., by increasing inflation when asset returns are high and decreasing inflation when asset returns are low. If this policy is implemented, the aggregate savings portfolio of old agents is risk-free.

\section{Bibliography}

Ajello, A., Laubach, T., Lopez-Salido, D., and Nakata, T. (2016). Financial stability and optimal interest-rate policy. FEDS Working Paper No. 2016-06\%.

Altermatt, L. (2017). Inside money, investment, and unconventional monetary policy. University of Zurich, Department of Economics Working Paper No. $24 \%$.

Andolfatto, D. (2013). Incentive-feasible deflation. Journal of Monetary Economics, 60:383-390.

Aruoba, S. B. and Chugh, S. K. (2010). Optimal fiscal and monetary policy when money is essential. Journal of Economic Theory, 145(5):1618-1647.

Barro, R. J., Fernandez-Villaverde, J., Levintal, O., and Mollerus, A. (2017). Safe assets. NBER Working Paper 20652.

Beirne, J. and Fratzscher, M. (2013). The pricing of sovereign risk and contagion during the european sovereign debt crisis. Journal of International Money and Finance, 34:60-82.

Berentsen, A. and Waller, C. (2011). Price level targeting and stabilization policy. Journal of Money, Credit and Banking, 43(2):559-580.

Berentsen, A. and Waller, C. (2015). Optimal stabilization policy with search externalities. Macroeconomic Dynamics, 19(3):669-700. 
Bernanke, B. S., Bertaut, C., DeMarco, L. P., and Kamin, S. (2011). International capital flows and the return to safe asset in the United States, 2003-2007. International Finance Discussion Paper 1014, Federal Reserve Board of Governors.

Bernanke, B. S. and Gertler, M. (2001). Should central banks respond to movements in asset prices? The American Economic Review, 91(2):253-257.

Bewley, T. (1983). A difficulty with the optimum quantity of money. Econometrica, 51(5):14851504.

Caballero, R. J. and Farhi, E. (2018). The safety trap. The Review of Economic Studies, 85(1):223274.

Caballero, R. J., Farhi, E., and Gourinchas, P.-O. (2008). An equilibrium model of "global imbalances" and low interest rates. American Economic Review, 98(1):358-393.

Caballero, R. J., Farhi, E., and Gourinchas, P.-O. (2017). The safe asset shortage conundrum. Journal of Economic Perspectives, 31(3):29-46.

Caballero, R. J. and Krishnamurthy, A. (2009). Global imbalances and financial fragility. American Economic Review Papers and Proceedings.

Cochrane, J. H. (2017). The new-Keynesian liquidity trap. Journal of Monetary Economics, 92:47-63.

Covitz, D., Liang, N., and Suarez, G. A. (2013). The evolution of a financial crisis: Collapse of the asset-backed commercial paper market. The Journal of Finance, 68(3).

Eggertsson, G. B. and Krugman, P. R. (2012). Debt, deleveraging, and the liquidity trap: A Fisher-Minsky-Koo approach. The Quarterly Journal of Economics, 127(3):1469-1513.

Eggertsson, G. B. and Woodford, M. (2003). The zero bound on interest rates and optimal monetary policy. Brookings Papers on Economic Activity, pages 139-233.

Eggertsson, G. B. and Woodford, M. (2004). Policy options in a liquidity trap. American Economic Review, 94(2):76-79.

Falato, A., Kadyrzhanova, D., Sim, J., and Steri, R. (2018). Rising intangible capital, shrinking debt capacity, and the us corporate savings glut. mimeo.

Gali, J. (2014). Monetary policy and rational asset price bubbles. American Economic Review, 104(3):721-752. 
Gali, J. (2017). Monetary policy and bubbles in a new Keynesian model with overlapping generations. Department of Economics and Business, Unviersitat Pompeu Fabra Economics Working Papers.

Geromichalos, A. and Herrenbrueck, L. (2017). The liquidity-augmented model of macroeconomic aggregates. Simon Fraser University, Department of Economics Working Paper 17-16.

Geromichalos, A., Herrenbrueck, L., and Lee, S. (2018). Asset safety versus asset liquidity. Working Paper, No 99-14, UC Davis.

Geromichalos, A., Licari, J. M., and Suarez-Lledo, J. (2007). Monetary policy and asset prices. Review of Economic Dynamics, 10(4):761-779.

Gomis-Porqueras, P. and Peralta-Alva, A. (2010). Optimal monetary and fiscal policies in a search theoretic model of monetary exchange. European Economic Review, 54(3):331-344.

Guerrieri, V. and Lorenzoni, G. (2017). Credit crises, precautionary savings, and the liquidity trap. The Quarterly Journal of Economics, 132(3):1427-1467.

He, Z., Krishnamurthy, A., and Milbradt, K. (2015). A model of the reserve asset. mimeo Chicago Booth.

Hiraguchi, R. (2017). Optimal monetary policy in an overlapping generations model with search theoretic monetary exchange. The B.E. Journal of Theoretical Economics, 17(2).

Jacquet, N. L. and Tan, S. (2011). Money, bargaining, and risk sharing. Journal of Money, Credit and Banking, 43:419-442.

Krugman, P. R., Dominguez, K. M., and Rogoff, K. (1998). It's baaack: Japan's slump and the return of the liquidity trap. Brookings Papers on Economic Activity, 1998(2):137-205.

Lagos, R. (2010). Asset prices and liquidity in an exchange economy. Journal of Monetary Economics, 57:913-930.

Lagos, R. and Wright, R. (2005). A unified framework for monetary theory and policy analysis. Journal of Political Economy, 113 (3):463-484.

Lester, B., Postlewaite, A., and Wright, R. (2012). Information, liquidity, asset prices, and monetary policy. Review of Economic Studies, 79:1209-1238.

Nistico, S. (2012). Monetary policy and stock-price dynamics in a DSGE framework. Journal of Macroeconomics, 34(1):126-146. 
Rocheteau, G. and Wright, R. (2005). Money in search equilibrium, in competitive equilibrium, and in competitive search equilibrium. Econometrica, 73(1):175-202.

Rocheteau, G., Wright, R., and Xiao, S. X. (2017). Open market operations. 2017 Meeting Papers 345, Society for Economic Dynamics.

Schularick, M. and Taylor, A. M. (2012). Credit booms gone bust: Monetary policy, leverage cycle, and financial crises, 1870-2008. American Economic Review, 102(2):1029-1061.

Stein, J. (2012). Monetary policy as financial-stability regulation. Quarterly Journal of Economics, 127(1):57-95.

Taylor, J. B. (2014). The role of policy in the great recession and the weak recovery. American Economic Review, 104(5):61-66.

Wallace, N. (1980). The overlapping generations model of fiat money. Models of Monetary Economies, Federal Reserve Bank of Minneapolis, pages 49-82.

Waller, C. (2009). Dynamic taxation, private information and money. Federal Reserve Bank of St. Louis Working Paper 2009-035A.

Williamson, S. (2012). Liquidity, monetary policy, and the financial crisis: A new monetarist approach. American Economic Review, 102 (6):2570-2605.

Williamson, S. (2016). Scarce collateral, the term premium, and quantitative easing. Journal of Economic Theory, 164:136-165.

Zhu, T. (2008). An overlapping-generations model with search. Journal of Economic Theory, 142(1):318-331. 


\section{Appendix A}

\section{A.1 Liquid bonds}

In this section, I will allow bonds to be partially liquid in DM transactions in order to analyze how this changes the results of the model. I will do this in the simpler version of the model where only bonds and fiat money, but no risky assets are available, as described in Section 3.1. However, I will give some intuition on how the full model would be affected by allowing for partial liquidity of bonds and risky assets after deriving the results in the reduced model.

Specifically, I assume that there is a share of sellers $\eta$ that is accepting both bonds and fiat money in the DM, while the remaining share of sellers $1-\eta$ does only accept fiat money. This is in line with e.g. Lester et al. (2012) or Williamson (2012). Because agents are matched at random in the DM, buyers do not know ex-ante whether they will be able to use bonds during the DM. I will call meetings where only money can be used monetary meetings, and meetings where both money and bonds can be used nonmonetary meetings.

With this change to the model, the lifetime value function of a buyer becomes

$$
\begin{gathered}
W=\max _{\substack{h_{t}^{y}, m_{t}^{y}, b_{t}^{y}, d_{t}^{b}, d_{t}^{m}}}-h_{t}^{y}+\eta\left(u\left(\beta \phi_{t+1} d_{t}^{b}\right)+\beta U\left(\phi_{t+1}\left(m_{t}^{y}+b_{t}^{y}-d_{t}^{b}\right)\right)\right) \\
\quad+(1-\eta)\left(u\left(\beta \phi_{t+1} d_{t}^{m}\right)+\beta U\left(\phi_{t+1}\left(m_{t}^{y}+b_{t}^{y}-d_{t}^{m}\right)\right)\right) \\
\text { s.t. } \quad h_{t}^{y}-\tau_{t}=\phi_{t}\left(m_{t}^{y}+p_{b, t} b_{t}^{y}\right) \\
\text { s.t. } \quad d_{t}^{b} \leq m_{t}^{y}+b_{t}^{y} \\
\text { s.t. } \quad d_{t}^{m} \leq m_{t}^{y} .
\end{gathered}
$$

In equation (30), $m_{t}^{y}$ stands for total money holdings of young buyers ${ }^{16}, d_{t}^{b}$ stands for nominal assets transferred in nonmonetary DM meetings, and $d_{t}^{m}$ stands for nominal assets transferred in monetary DM meetings. The rest of the notation is the same as in the rest of the paper. The last two constraints say that agents cannot spend more nominal assets than they have during DM meetings, and specify which assets can be used to trade. Note that the penultimate constraint never binds, because otherwise buyers wouldn't have any funds left for CM consumption, which violates the Inada conditions.

\footnotetext{
${ }^{16}$ Note that this is a change in notation compared to the rest of the paper, where $m_{t}^{y}$ stood only for money held for savings purposes.
} 
Solving this problem gives rise to the following conditions:

$$
\begin{aligned}
1 & \geq p_{b, t} \\
m_{t}^{y}-d_{t}^{m} & \geq 0 \\
u^{\prime}\left(\beta \phi_{t+1} d_{t}^{b}\right) & =U^{\prime}\left(\phi_{t+1}\left(m_{t}^{y}+b_{t}^{y}-d_{t}^{b}\right)\right) \\
\frac{\phi_{t}}{\phi_{t+1}} \frac{p_{b, t}}{\beta} & =\eta U^{\prime}\left(\phi_{t+1}\left(m_{t}^{y}+b_{t}^{y}-d_{t}^{b}\right)\right)+(1-\eta) U^{\prime}\left(\phi_{t+1}\left(m_{t}^{y}+b_{t}^{y}-d_{t}^{m}\right)\right) \\
\frac{\phi_{t}}{\phi_{t+1}} \frac{1}{\beta} & =\eta U^{\prime}\left(\phi_{t+1}\left(m_{t}^{y}+b_{t}^{y}-d_{t}^{b}\right)\right)+(1-\eta) u^{\prime}\left(\beta \phi_{t+1} d_{t}^{m}\right) \\
b_{t}^{y}+b_{t}^{s} & =\frac{B_{t}}{N_{t}} \quad \text { with } b_{t}^{s}=0 \text { if } p_{b, t}=p_{b}^{*}, \text { and } b_{t}^{s}=\frac{B_{t}}{N_{t}}-b_{t}^{y} \text { otherwise. }
\end{aligned}
$$

Either equation (31) or (32) has to hold with equality, meaning that the upper bound on the bond price is 1 , and buyers spend all their money holdings in DM meetings where bonds are not accepted unless we are at the zero lower bound (i.e., $p_{b, t}=1$ ). Equation (33) shows that buyers always equalize marginal utility across DM and CM if they have a DM meeting where bonds are accepted. Equation (34) equalizes the cost of holding bonds with the benefit of doing so, and equation (35) does the same for money. Finally, equation (36) denotes the market clearing condition for bonds.

While the assumption of liquid bonds makes the model more intricate, the core mechanisms of the version with illiquid bonds still hold. The bond price is still bounded above by 1 and below by $p_{b}^{*}$, and for prices inbetween these bounds, the bond price is decreasing with an increase in the bond supply. The bond supply $\underline{\mathcal{B}}$, corresponding to the upper bound on the bond price, can be found by solving the above system for $B_{t}$ in the case where both (31) and (32) hold with equality, and $\mathcal{B}^{*}$ (corresponding to the lower bound) can be found by solving the system for $B_{t}$ in the case of $p_{b, t}=p_{b}^{*}$ and $b_{t}^{s}=0$ holding simultaneously. While there is no difference qualitatively, quantitatively there is a change, because bond demand now consists of two components, i.e., old age savings and liquidity properties. This means that both $\underline{\mathcal{B}}$ and $\mathcal{B}^{*}$ are larger numbers compared to the version with illiquid bonds if all other parameters stay unchanged, which in turn means that a zero lower bound is more likely, and a larger supply of government bonds is required to reach $p_{b}^{*}$.

The model is more intricate mainly when it comes to its welfare properties. The uncertainty about the DM meeting creates a friction that can only be overcome by implementing the Friedman rule. Away from the Friedman rule, even a bond supply of $\mathcal{B}^{*}$ does not ensure first-best consumption in the $\mathrm{CM}$, even though it is still welfare maximizing. If $\mathcal{B}_{t} \geq \mathcal{B}^{*}$, buyers that have monetary 
meetings in the DM will consume more than $x^{*}$ in the $\mathrm{CM}$, while buyers with nonmonetary meetings in the DM will consume less than $x^{*}$. This is because all buyers hold a total amount of liquid assets that is less than what would be required to purchase the first-best quantities in both markets, but they also hold more bonds than required to purchase the first-best CM consumption. In case of a monetary meeting, they spend all their money (which is not enough to get them $q^{*}$ ), but then they are left with too many bonds for CM consumption, because they were holding some bonds for the case they could use them during the DM. In case they have a nonmonetary meeting, buyers can use all assets in both markets, so they want to equalize marginal utility. But since they are holding less assets than required to purchase the first-best in both markets, their consumption will be below first-best in both markets.

At the zero lower bound, buyers equalize marginal utility across all four states. This is straightforward, because money and bonds have the same return at the zero lower bound, so buyers cannot economize on money holdings in order to obtain higher returns by holding bonds, so the uncertainty about the kind of DM meeting does not matter. From equation (33), we know that marginal utility is always equalized across DM and CM for nonmonetary meetings, and combining equations (34) and (35) shows that the same is true for monetary meetings in the case of $p_{b, t}=1$. Because the total assets a buyer holds are the same in both cases, this implies that marginal utility has to be the same across all four states/markets. This eliminates uncertainty about consumption, but buyers are consuming less than the first-best in all markets and states, so this is actually the state with the lowest welfare (for a given inflation rate).

To sum up, allowing for liquid bonds only changes the model quantitatively in terms of asset pricing and welfare-maximizing policies. It does however add uncertainty to both DM and old-age $\mathrm{CM}$ consumption levels for buyers away from the zero-lower bound.

\section{A.2 Liquid bonds and risky assets}

Having liquid bonds in the full model leads to two states for DM consumption, and four states for old-age CM consumption (two states due to the uncertainty about asset return, and two states due to the uncertainty about the DM meeting). With partially liquid risky assets on top of that, there are three states for DM consumption, and six states for old-age CM consumption, if liquidity of risky assets is supposed to be different from liquidity of bonds, but is otherwise modeled in 
the simplest way possible ${ }^{17}$. While it is not impossible to solve such a model, the equilibrium conditions wouldn't be very informative anymore. However, the above analysis allows to make a conjecture about how the model would change by making all assets liquid.

First, let us consider the case of liquid bonds, but fully illiquid risky assets. The above analysis has shown that this leads to an increase in both $\underline{\mathcal{B}}$ and $\mathcal{B}^{*}$ ceteris paribus. Regarding figures 6 and 7 , this means that the areas of equilibrium regions IVa, and $\mathrm{IVb}^{18}$ would gain in size and thus become more likely to occur, while regions I and II would become less likely to occur. It is unclear whether region III would increase or decrease, as this depends on the relative increases in $\underline{\mathcal{B}}$ and $\mathcal{B}^{*}$.

If risky assets can be used in the DM, demand for them will also increase for any given price (they are still as good as before in providing old-age consumption, but they can also be used to provide for DM consumption now). This means that $\tilde{A}$ and $A^{*}$ will both increase ceteris paribus. For a given liquidity of bonds (either zero or positive), an increase in the liquidity of risky assets makes region IVa more likely while regions IVb and II become less likely. Again, the effect on region III is not clear, while region I is not affected, because no risky assets are held in that region.

\section{Appendix B}

\section{B.1 How to implement the optimal stabilization policy}

For the monetary authority to pick the correct values of money in period $t+1$ in order to make the buyers' portfolio risk-free, it needs to know which portfolio the agents are going to choose. In equilibrium regions III and IVa, buyers hold all assets available, so $N_{t} a_{t}^{y}=A_{t}$ and $N_{t} b_{t}^{y}=B_{t}$. Thus, the monetary authority knows the buyers' portfolio and can choose the value of money in the next period given equation (27), the current value of money, and its inflation target such that (28) holds. Prices will then adjust such that (29) is satisfied ${ }^{19}$.

In equilibrium regions II and IVb, buyers do not hold all assets, and thus it becomes more complex for the monetary authority to know which portfolio buyers will choose to hold. However, bonds are still in short supply, so $N_{t} b_{t}^{y}=B_{t}$ still holds. This means that $a_{t}^{y}$ also becomes a decision

\footnotetext{
${ }^{17}$ By assuming that there are three kinds of DM meetings: Either a seller accepts only fiat money, he accepts only fiat money and bonds, or he accepts all assets.

${ }^{18}$ The length of the horizontal line originating at $A^{*}$ depends on the amount of bonds that is required for the interest rate to increase above zero if risky asset prices are unconstrained.

${ }^{19}$ In equilibrium region IVa, buyers might still want to save with all three assets, i.e., they also hold some money. This is the case if $p_{b, t}=1$. In this case, (28) becomes $\kappa^{H} a_{t}^{y}+\phi_{t+1}^{L}\left(b_{t}^{y}+m_{t}^{y}\right)=\kappa^{L} a_{t}^{y}+\phi_{t+1}^{H}\left(b_{t}^{y}+m_{t}^{y}\right)$, and the monetary authority has to adjust its policy accordingly.
} 
variable for the central bank, and it can choose this variable such that

$$
\kappa^{H} a_{t}^{y}+\phi_{t+1}^{L} \frac{B_{t}}{N_{t}}=\kappa^{L} a_{t}^{y}+\phi_{t+1}^{H} \frac{B_{t}}{N_{t}}=x^{*}
$$

holds, given that $N_{t} a_{t}^{y} \leq A_{t}$ and its choices for the value of money given equation (27). This policy will lead to the equilibrium prices $p_{b_{t}}=p_{b}^{*}$ and $p_{a, t}=1$, which also satisfy (29). 